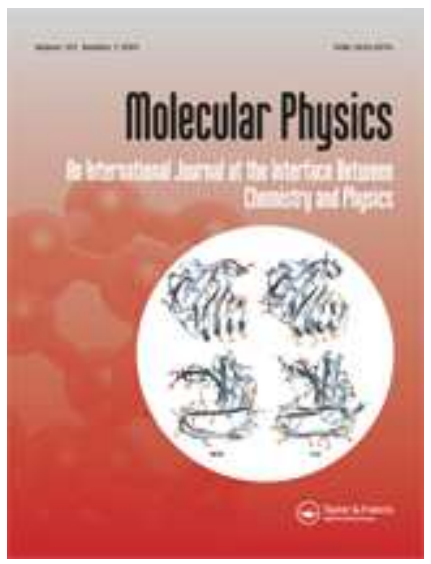

\title{
Basis set effects on coupled cluster benchmarks of electronically excited states: CC3, CCSDR(3) and CC2
}

\begin{tabular}{|c|c|}
\hline Journal: & Molecular Physics \\
\hline Manuscript ID: & TMPH-2009-0307.R1 \\
\hline Manuscript Type: & Special Issue Paper - In honour of Prof Werner 60th birthday \\
\hline $\begin{array}{r}\text { Date Submitted by the } \\
\text { Author: }\end{array}$ & 03-Dec-2009 \\
\hline Complete List of Authors: & $\begin{array}{l}\text { Silva-Junior, Mario; Max-Planck-Institut für Kohlenforschung, } \\
\text { Theory } \\
\text { Sauer, Stephan; University of Copenhagen, Department of } \\
\text { Chemistry } \\
\text { Schreiber, Marko; Max-Planck-Institut für Kohlenforschung, Theory } \\
\text { Thiel, Walter; Max-Planck-Institut für Kohlenforschung, Theory }\end{array}$ \\
\hline Keywords: & $\begin{array}{l}\text { electronically excited states, benchmarks, coupled cluster methods, } \\
\text { CC2, CCSDR(3), CC3 }\end{array}$ \\
\hline \multicolumn{2}{|c|}{$\begin{array}{l}\text { Note: The following files were submitted by the author for peer review, but cannot be converted } \\
\text { to PDF. You must view these files (e.g. movies) online. }\end{array}$} \\
\hline $\begin{array}{l}\text { paper.tex } \\
\text { table1.tex } \\
\text { appendix1.tex } \\
\text { appendix2.tex } \\
\text { appendix3.tex }\end{array}$ & \\
\hline
\end{tabular}




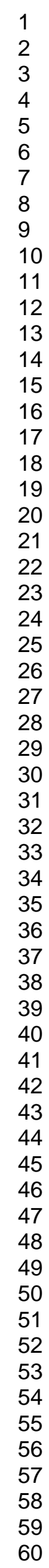

\section{$\$$ Manuscript Central}

URL: http://mc.manuscriptcentral.com/tandf/tmph 


\title{
RESEARCH ARTICLE
}

\section{Basis set effects on coupled cluster benchmarks of electronically excited states: CC3, CCSDR(3) and CC2}

\author{
Mario R. Silva-Junior ${ }^{a}$, Stephan P.A. Sauer ${ }^{b \dagger}$, Marko Schreiber $^{a}$ and Walter Thiel ${ }^{a *}$ \\ ${ }^{a}$ Max-Planck-Institut für Kohlenforschung, Kaiser-Wilhelm-Platz 1, D-45470 Mülheim an \\ der Ruhr, Germany; ${ }^{b}$ Department of Chemistry, University of Copenhagen, DK-2100 \\ Copenhagen $\varnothing$, Denmark
}

(1st October 2009)

\begin{abstract}
Vertical electronic excitation energies and one-electron properties of 28 medium-size molecules from a previously proposed benchmark set are revisited using the augmented correlationconsistent triple-zeta aug-cc-pVTZ basis set in CC2, CCSDR(3), and CC3 calculations. The results are compared to those obtained previously with the smaller TZVP basis set. For each of the three coupled cluster methods, a correlation coefficient greater than 0.994 is found between the vertical excitation energies computed with the two basis sets. The deviations of the CC2 and CCSDR(3) results from the CC3 reference values are very similar for both basis sets, thus confirming previous conclusions on the intrinsic accuracy of CC2 and CCSDR(3). This similarity justifies the use of CC2- or CCSDR(3)-based corrections to account for basis set incompleteness in CC3 studies of vertical excitation energies. For oscillator strengths and excited-state dipole moments, CC2 calculations with the aug-cc-pVTZ and TZVP basis sets give correlation coefficients of 0.966 and 0.833 , respectively, implying that basis set convergence is slower for these one-electron properties.
\end{abstract}

Keywords: electronically excited states; benchmarks; coupled cluster methods; CC2; CCSDR(3); CC3.

\section{Introduction}

The importance of an accurate reference data set for excited-state energies and properties is unquestionable. Recently, we introduced a benchmark set [1-3] for vertical electronic excitation energies of 28 medium-sized molecules which represent the most significant organic chromophores. Theoretical best estimates were derived [1] from linear response CC3 and multistate CASPT2 calculations as well as high-level $a b$ initio literature values. The main purpose of such a comprehensive reference data set is the validation of existing as well as newly developed methods and the parametrization of semiempirical or other adjustable methods. The proposed reference set has already been used in the validation of lower-level coupled cluster methods and approaches based on density functional theory [2-5].

In our previous work we employed a TZVP basis set [6] which was considered sufficiently flexible for the low-lying valence excited states that were of prime interest in our benchmarking. This choice of a medium-size basis set also enabled us to treat the majority of the reference molecules at the CC3 level. Since the TZVP basis lacks diffuse functions, it is less appropriate for higher-lying valence states

\footnotetext{
†Email: sauer@kiku.dk

*Corresponding author. Email: thiel@mpi-muelheim.mpg.de

ISSN: 00268976 print/ISSN 13623028 online

(C) 2009 Taylor \& Francis

DOI: $10.1080 / 0026897 \mathrm{YYxxxxxxxx}$

http://www.informaworld.com
} 
and for states which are spatially extended and have (partial) Rydberg character. Therefore, the proper identification of such states may become problematic when using the TZVP basis as in our previous studies [1-3], because the character of these higher-lying states might change upon basis set extension. Rydberg states can often be described effectively by adding a single set of very diffuse functions at the center of the molecule, as has e.g. been done for benzene or other polycyclic aromatic hydrocarbons (see Refs. [7,8] and references therein), but this is not a convenient option for molecules of arbitrary shape. Therefore, we previously studied [1] the basis set dependence of the vertical excitation energy of the high-lying $1^{1} \mathrm{~B}_{1 u}$ singlet state in ethene, which is known to be rather diffuse and susceptible to valence-Rydberg mixing, using twelve different correlation consistent basis sets $[9,10]$. When comparing against the essentially converged excitation energies computed with the most extended aug-cc-pV5Z and d-aug-cc-pVQZ basis sets, we found differences of more than $0.4 \mathrm{eV}$ for the results with the TZVP basis, but excellent agreement for those with the aug-cc-pVTZ basis (deviations of less than $0.1 \mathrm{eV})$.

In this work we use the aug-cc-pVTZ basis set $[9,10]$ in a comprehensive study that includes all 28 original benchmark molecules in CC2 calculations and subsets of 21 and 8 molecules at the $\operatorname{CCSDR}(3)$ and CC3 levels, respectively. This basis set was chosen because it has been proven to be adequate in coupled cluster calculations of high-lying singlet states not only in the case of ethene [1], but also for a number of other chromophores (see e.g. Refs. [11-15]). However, even the aug-cc-pVTZ basis set is not optimal for Rydberg states in general, and hence additional molecule-centered diffuse basis functions may be necessary for an accurate description of states with significant valence-Rydberg mixing.

The paper is organized as follows: Computational details are described in the next section. The results for the aug-cc-pVTZ basis are presented and compared to those for the TZVP basis in the following section which also provides various statistical evaluations. The final section offers a summary.

\section{Computational Details}

All calculations were performed at the MP2/6-31G* optimized ground-state geometries [1] using the augmented aug-cc-pVTZ $[9,10]$ basis. The $\operatorname{CCSDR}(3)[16,17]$ and CC3 $[11,18,19]$ computations were carried out with the Dalton 2.0 program package [20]. Only singlet states were calculated, with the core electrons being frozen during the coupled cluster calculations which causes negligible deviations (less than $0.01 \mathrm{eV}$ ) compared with a fully correlated all-electron treatment [7].

The CC2 [21, 22] calculations were done with the parallel version of program RICC2 [23-26] from the TURBOMOLE package (version 5.10) [27], employing the resolution-of-identity approximation $[28,29]$ and the appropriate auxiliary basis set provided by the TURBOMOLE library $[30,31]$. In the case of CC2, both singlet and triplet excitation energies as well as one-electron properties (dipole moments and oscillator strengths in dipole length representation) were computed. It should be noted that the presence of diffuse functions in the basis set makes the assignment of states more difficult. As in our previous work $[1,3]$, we used the expectation value $\left\langle\mathrm{r}^{2}\right\rangle$ as one of the criteria to determine the valence character of a given excited state and to identify valence-Rydberg mixings which can be pronounced especially in the high-lying states. 
Table 1.: Vertical excitation energies $\Delta E(\mathrm{eV})$ of singlet excited states from coupled-cluster calculations with the TZVP $^{a}$ and aug-cc-pVTZ ${ }^{b}$ basis sets.

\begin{tabular}{|c|c|c|c|c|c|c|c|}
\hline \multirow{2}{*}{ Molecule } & \multirow[t]{2}{*}{ State } & \multicolumn{2}{|r|}{$\mathrm{CC} 2$} & \multicolumn{2}{|c|}{$\operatorname{CCSDR}(3)$} & \multicolumn{2}{|r|}{$\mathrm{CC} 3$} \\
\hline & & TZVP & aug-cc-pVTZ & TZVP & aug-cc-pVTZ & TZVP & aug-cc-pVTZ \\
\hline Ethene & $1^{1} \mathrm{~B}_{1 u}\left(\pi \rightarrow \pi^{*}\right)$ & 8.40 & 7.90 & 8.37 & 7.87 & 8.37 & 7.89 \\
\hline E-Butadiene & $\begin{array}{l}1^{1} \mathrm{~B}_{u}\left(\pi \rightarrow \pi^{*}\right) \\
2^{1} \mathrm{~A}_{g}\left(\pi \rightarrow \pi^{*}\right)\end{array}$ & $\begin{array}{l}6.49 \\
7.63\end{array}$ & $\begin{array}{l}6.13 \\
7.06\end{array}$ & $\begin{array}{l}6.56 \\
6.95\end{array}$ & $\begin{array}{l}6.19 \\
6.82\end{array}$ & 6.77 & 6.63 \\
\hline all-E-Hexatriene & $\begin{array}{l}1^{1} \mathrm{~B}_{u}\left(\pi \rightarrow \pi^{*}\right) \\
2^{1} \mathrm{~A}_{g}\left(\pi \rightarrow \pi^{*}\right)\end{array}$ & $\begin{array}{l}5.41 \\
6.67\end{array}$ & $\begin{array}{l}5.18 \\
6.43\end{array}$ & $\begin{array}{l}5.56 \\
6.04\end{array}$ & $\begin{array}{l}5.30 \\
6.09\end{array}$ & & \\
\hline all-E-Octatetraene & $\begin{array}{l}2^{1} \mathrm{~A}_{g}\left(\pi \rightarrow \pi^{*}\right) \\
1^{1} \mathrm{~B}_{u}\left(\pi \rightarrow \pi^{*}\right) \\
2^{1} \mathrm{~B}_{u}\left(\pi \rightarrow \pi^{*}\right) \\
3^{1} \mathrm{~A}_{g}\left(\pi \rightarrow \pi^{*}\right) \\
4^{1} \mathrm{~A}_{g}\left(\pi \rightarrow \pi^{*}\right)\end{array}$ & $\begin{array}{l}5.87 \\
4.72 \\
6.91 \\
6.72 \\
7.01\end{array}$ & $\begin{array}{l}5.74 \\
4.53 \\
6.37 \\
6.12 \\
6.36\end{array}$ & & & & \\
\hline Cyclopropene & $\begin{array}{l}{ }^{1} \mathrm{~B}_{1}\left(\sigma \rightarrow \pi^{*}\right) \\
1^{1} \mathrm{~B}_{2}\left(\pi \rightarrow \pi^{*}\right)\end{array}$ & $\begin{array}{l}6.96 \\
7.17\end{array}$ & $\begin{array}{l}6.73 \\
6.72\end{array}$ & $\begin{array}{l}6.89 \\
7.10\end{array}$ & $\begin{array}{l}6.67 \\
6.68\end{array}$ & $\begin{array}{l}6.90 \\
7.10\end{array}$ & $\begin{array}{l}6.67 \\
6.68\end{array}$ \\
\hline Cyclopentadiene & $\begin{array}{l}1^{1} \mathrm{~B}_{2}\left(\pi \rightarrow \pi^{*}\right) \\
2^{1} \mathrm{~A}_{1}\left(\pi \rightarrow \pi^{*}\right) \\
3^{1} \mathrm{~A}_{1}\left(\pi \rightarrow \pi^{*}\right)\end{array}$ & $\begin{array}{l}5.69 \\
7.05 \\
8.86\end{array}$ & $\begin{array}{l}5.47 \\
6.80 \\
8.19\end{array}$ & $\begin{array}{l}5.72 \\
6.76 \\
8.72\end{array}$ & $\begin{array}{l}5.48 \\
6.64 \\
8.17\end{array}$ & & \\
\hline Norbornadiene & $\begin{array}{l}1^{1} \mathrm{~A}_{2}\left(\pi \rightarrow \pi^{*}\right) \\
1^{1} \mathrm{~B}_{2}\left(\pi \rightarrow \pi^{*}\right)\end{array}$ & $\begin{array}{l}5.57 \\
6.37\end{array}$ & $\begin{array}{l}5.30 \\
6.09\end{array}$ & & & & \\
\hline
\end{tabular}


Table 1 - Continued

\begin{tabular}{|c|c|c|c|c|c|c|c|}
\hline \multirow[t]{2}{*}{ Molecule } & \multirow[t]{2}{*}{ State } & \multicolumn{2}{|r|}{$\mathrm{CC} 2$} & \multicolumn{2}{|c|}{$\operatorname{CCSDR}(3)$} & \multicolumn{2}{|r|}{$\mathrm{CC} 3$} \\
\hline & & TZVP & aug-cc-pVTZ & TZVP & aug-cc-pVTZ & TZVP & aug-cc-pVTZ \\
\hline 8 & $\begin{array}{l}2^{1} \mathrm{~B}_{2}\left(\pi \rightarrow \pi^{*}\right) \\
2^{1} \mathrm{~A}_{2}\left(\pi \rightarrow \pi^{*}\right)\end{array}$ & $\begin{array}{l}7.65 \\
7.66\end{array}$ & $\begin{array}{l}7.50 \\
7.17\end{array}$ & & & & \\
\hline Benzene & $\begin{array}{l}{ }^{1} \mathrm{~B}_{2 u}\left(\pi \rightarrow \pi^{*}\right) \\
1^{1} \mathrm{~B}_{1 u}\left(\pi \rightarrow \pi^{*}\right) \\
1^{1} \mathrm{E}_{1 u}\left(\pi \rightarrow \pi^{*}\right) \\
2^{1} \mathrm{E}_{2 g}\left(\pi \rightarrow \pi^{*}\right)\end{array}$ & $\begin{array}{l}5.27 \\
6.68 \\
7.44 \\
9.03\end{array}$ & $\begin{array}{l}5.22 \\
6.45 \\
7.12 \\
8.49\end{array}$ & $\begin{array}{l}5.12 \\
6.70 \\
7.45 \\
8.71\end{array}$ & $\begin{array}{l}5.09 \\
6.44 \\
7.16 \\
8.56\end{array}$ & $\begin{array}{l}5.07 \\
6.68 \\
7.45 \\
8.43\end{array}$ & $\begin{array}{l}5.03 \\
6.42 \\
7.14 \\
8.31\end{array}$ \\
\hline Naphthalene & $\begin{array}{l}1^{1} \mathrm{~B}_{3 u}\left(\pi \rightarrow \pi^{*}\right) \\
1^{1} \mathrm{~B}_{2 u}\left(\pi \rightarrow \pi^{*}\right) \\
2^{1} \mathrm{~A}_{g}\left(\pi \rightarrow \pi^{*}\right) \\
1^{1} \mathrm{~B}_{1 g}\left(\pi \rightarrow \pi^{*}\right) \\
2^{1} \mathrm{~B}_{3 u}\left(\pi \rightarrow \pi^{*}\right) \\
2^{1} \mathrm{~B}_{1 g}\left(\pi \rightarrow \pi^{*}\right) \\
2^{1} \mathrm{~B}_{2 u}\left(\pi \rightarrow \pi^{*}\right) \\
3^{1} \mathrm{~A}_{g}\left(\pi \rightarrow \pi^{*}\right) \\
3^{1} \mathrm{~B}_{2 u}\left(\pi \rightarrow \pi^{*}\right) \\
3^{1} \mathrm{~B}_{3 u}\left(\pi \rightarrow \pi^{*}\right)\end{array}$ & $\begin{array}{l}4.45 \\
4.96 \\
6.22 \\
6.21 \\
6.25 \\
6.82 \\
6.57 \\
7.34 \\
8.46 \\
8.85\end{array}$ & $\begin{array}{l}4.38 \\
4.75 \\
6.07 \\
5.82 \\
6.02 \\
6.44 \\
6.35 \\
7.10 \\
7.90 \\
8.66\end{array}$ & $\begin{array}{l}4.34 \\
5.08 \\
6.09 \\
6.26 \\
6.35 \\
6.81 \\
6.60 \\
7.29 \\
\end{array}$ & $\begin{array}{l}4.32 \\
4.87 \\
6.01 \\
5.94 \\
6.13 \\
6.48 \\
6.39 \\
7.25\end{array}$ & & \\
\hline Furan & $\begin{array}{l}1^{1} \mathrm{~B}_{2}\left(\pi \rightarrow \pi^{*}\right) \\
2^{1} \mathrm{~A}_{1}\left(\pi \rightarrow \pi^{*}\right) \\
3^{1} \mathrm{~A}_{1}\left(\pi \rightarrow \pi^{*}\right)\end{array}$ & $\begin{array}{l}6.75 \\
6.87 \\
8.78\end{array}$ & $\begin{array}{l}6.37 \\
6.70 \\
8.23\end{array}$ & $\begin{array}{l}6.64 \\
6.71 \\
8.57\end{array}$ & $\begin{array}{l}6.30 \\
6.60 \\
8.17\end{array}$ & & \\
\hline Pyrrole & $\begin{array}{l}2^{1} \mathrm{~A}_{1}\left(\pi \rightarrow \pi^{*}\right) \\
1^{1} \mathrm{~B}_{2}\left(\pi \rightarrow \pi^{*}\right)\end{array}$ & $\begin{array}{l}6.61 \\
6.88\end{array}$ & $\begin{array}{l}6.42 \\
6.85\end{array}$ & $\begin{array}{l}6.47 \\
6.74\end{array}$ & $\begin{array}{l}6.34 \\
6.23\end{array}$ & & \\
\hline
\end{tabular}

Continued on Next Page... 
Table 1 - Continued

\begin{tabular}{|c|c|c|c|c|c|c|c|}
\hline \multirow[t]{2}{*}{ Molecule } & \multirow[t]{2}{*}{ State } & \multicolumn{2}{|r|}{$\mathrm{CC} 2$} & \multicolumn{2}{|c|}{$\operatorname{CCSDR}(3)$} & \multicolumn{2}{|r|}{ CC3 } \\
\hline & & TZVP & aug-cc-pVTZ & TZVP & aug-cc-pVTZ & TZVP & aug-cc-pVTZ \\
\hline & $3^{1} \mathrm{~A}_{1}\left(\pi \rightarrow \pi^{*}\right)$ & 8.44 & 7.81 & 8.20 & 7.63 & & \\
\hline Imidazole & $\begin{array}{l}1^{1} \mathrm{~A}^{\prime \prime}\left(n \rightarrow \pi^{*}\right) \\
2^{1} \mathrm{~A}^{\prime}\left(\pi \rightarrow \pi^{*}\right) \\
3^{1} \mathrm{~A}^{\prime}\left(\pi \rightarrow \pi^{*}\right) \\
2^{1} \mathrm{~A}^{\prime \prime}\left(n \rightarrow \pi^{*}\right) \\
4^{1} \mathrm{~A}^{\prime}\left(\pi \rightarrow \pi^{*}\right)\end{array}$ & $\begin{array}{l}6.86 \\
6.73 \\
7.28 \\
8.00 \\
8.62\end{array}$ & $\begin{array}{l}6.69 \\
6.40 \\
6.91 \\
7.64 \\
8.68\end{array}$ & & & & \\
\hline Pyridine & $\begin{array}{l}1^{1} \mathrm{~B}_{2}\left(\pi \rightarrow \pi^{*}\right) \\
1^{1} \mathrm{~B}_{1}\left(n \rightarrow \pi^{*}\right) \\
1^{1} \mathrm{~A}_{2}\left(n \rightarrow \pi^{*}\right) \\
2^{1} \mathrm{~A}_{1}\left(\pi \rightarrow \pi^{*}\right) \\
3^{1} \mathrm{~A}_{1}\left(\pi \rightarrow \pi^{*}\right) \\
2^{1} \mathrm{~B}_{2}\left(\pi \rightarrow \pi^{*}\right) \\
3^{1} \mathrm{~B}_{2}\left(\pi \rightarrow \pi^{*}\right) \\
4^{1} \mathrm{~A}_{1}\left(\pi \rightarrow \pi^{*}\right)\end{array}$ & $\begin{array}{l}5.32 \\
5.12 \\
5.39 \\
6.88 \\
7.72 \\
7.61 \\
9.37 \\
9.00\end{array}$ & $\begin{array}{l}5.26 \\
4.97 \\
5.27 \\
6.64 \\
7.43 \\
7.32 \\
8.03 \\
8.59\end{array}$ & $\begin{array}{l}5.20 \\
5.12 \\
5.55 \\
6.88 \\
7.72 \\
7.61 \\
9.09 \\
9.00\end{array}$ & $\begin{array}{l}5.17 \\
5.02 \\
5.46 \\
6.63 \\
7.41 \\
7.35 \\
8.04 \\
8.65\end{array}$ & & \\
\hline Pyrazine & $\begin{array}{l}1^{1} \mathrm{~B}_{3 u}\left(n \rightarrow \pi^{*}\right) \\
1^{1} \mathrm{~A}_{u}\left(n \rightarrow \pi^{*}\right) \\
1^{1} \mathrm{~B}_{2 u}\left(\pi \rightarrow \pi^{*}\right) \\
1^{1} \mathrm{~B}_{2 g}\left(n \rightarrow \pi^{*}\right) \\
1^{1} \mathrm{~B}_{1 g}\left(n \rightarrow \pi^{*}\right) \\
1^{1} \mathrm{~B}_{1 u}\left(\pi \rightarrow \pi^{*}\right) \\
2^{1} \mathrm{~B}_{1 u}\left(\pi \rightarrow \pi^{*}\right) \\
2^{1} \mathrm{~B}_{2 u}\left(\pi \rightarrow \pi^{*}\right)\end{array}$ & $\begin{array}{l}4.26 \\
4.95 \\
5.13 \\
5.92 \\
6.70 \\
7.10 \\
8.13 \\
8.07\end{array}$ & $\begin{array}{l}4.12 \\
4.86 \\
5.07 \\
5.79 \\
6.61 \\
6.86 \\
7.92 \\
7.82\end{array}$ & $\begin{array}{l}4.31 \\
5.11 \\
5.07 \\
5.86 \\
6.86 \\
7.10 \\
8.09 \\
8.08\end{array}$ & $\begin{array}{l}4.20 \\
5.05 \\
5.02 \\
5.77 \\
6.80 \\
6.86 \\
7.89 \\
7.84\end{array}$ & & \\
\hline
\end{tabular}

Continued on Next Page. . 
Table 1 - Continued

\begin{tabular}{|c|c|c|c|c|c|c|c|}
\hline \multirow[t]{2}{*}{ Molecule } & \multirow[t]{2}{*}{ State } & \multicolumn{2}{|r|}{$\mathrm{CC} 2$} & \multicolumn{2}{|c|}{$\operatorname{CCSDR}(3)$} & \multicolumn{2}{|r|}{$\mathrm{CC} 3$} \\
\hline & & TZVP & aug-cc-pVTZ & TZVP & aug-cc-pVTZ & TZVP & aug-cc-pVTZ \\
\hline 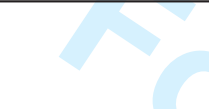 & $\begin{array}{l}1^{1} \mathrm{~B}_{3 g}\left(\pi \rightarrow \pi^{*}\right) \\
2^{1} \mathrm{~A}_{g}\left(\pi \rightarrow \pi^{*}\right)\end{array}$ & $\begin{array}{l}9.42 \\
9.26\end{array}$ & $\begin{array}{l}9.00 \\
9.08\end{array}$ & $\begin{array}{l}9.16 \\
9.04\end{array}$ & $\begin{array}{l}9.08 \\
9.13\end{array}$ & & \\
\hline Pyrimidine & $\begin{array}{l}1^{1} \mathrm{~B}_{1}\left(n \rightarrow \pi^{*}\right) \\
1^{1} \mathrm{~A}_{2}\left(n \rightarrow \pi^{*}\right) \\
1^{1} \mathrm{~B}_{2}\left(\pi \rightarrow \pi^{*}\right) \\
2^{1} \mathrm{~A}_{1}\left(\pi \rightarrow \pi^{*}\right) \\
2^{1} \mathrm{~B}_{2}\left(\pi \rightarrow \pi^{*}\right) \\
3^{1} \mathrm{~A}_{1}\left(\pi \rightarrow \pi^{*}\right)\end{array}$ & $\begin{array}{l}4.49 \\
4.84 \\
5.51 \\
7.12 \\
8.08 \\
7.79\end{array}$ & $\begin{array}{l}4.37 \\
4.75 \\
5.46 \\
6.94 \\
7.82 \\
7.53\end{array}$ & $\begin{array}{l}4.56 \\
4.97 \\
5.42 \\
7.10 \\
8.02 \\
7.77\end{array}$ & $\begin{array}{l}4.48 \\
4.90 \\
5.40 \\
6.86 \\
7.83 \\
7.56\end{array}$ & & \\
\hline Pyridazine & $\begin{array}{l}1^{1} \mathrm{~B}_{1}\left(n \rightarrow \pi^{*}\right) \\
1^{1} \mathrm{~A}_{2}\left(n \rightarrow \pi^{*}\right) \\
2^{1} \mathrm{~A}_{1}\left(\pi \rightarrow \pi^{*}\right) \\
2^{1} \mathrm{~A}_{2}\left(n \rightarrow \pi^{*}\right) \\
2^{1} \mathrm{~B}_{1}\left(n \rightarrow \pi^{*}\right) \\
1^{1} \mathrm{~B}_{2}\left(\pi \rightarrow \pi^{*}\right) \\
2^{1} \mathrm{~B}_{2}\left(\pi \rightarrow \pi^{*}\right) \\
3^{1} \mathrm{~A}_{1}\left(\pi \rightarrow \pi^{*}\right)\end{array}$ & $\begin{array}{l}3.90 \\
4.40 \\
5.37 \\
5.81 \\
6.40 \\
7.00 \\
7.57 \\
7.90\end{array}$ & $\begin{array}{l}3.79 \\
4.30 \\
5.32 \\
5.70 \\
6.27 \\
6.79 \\
7.33 \\
7.70\end{array}$ & $\begin{array}{l}3.99 \\
4.57 \\
5.28 \\
5.84 \\
6.49 \\
6.99 \\
7.58 \\
7.86\end{array}$ & $\begin{array}{l}3.92 \\
4.52 \\
5.26 \\
5.76 \\
6.41 \\
6.74 \\
7.36 \\
7.58\end{array}$ & & \\
\hline$s$-triazine & $\begin{array}{l}1^{1} \mathrm{~A}_{1}^{\prime \prime}\left(n \rightarrow \pi^{*}\right) \\
1^{1} \mathrm{~A}_{2}^{\prime \prime}\left(n \rightarrow \pi^{*}\right) \\
1^{1} \mathrm{E}^{\prime \prime}\left(n \rightarrow \pi^{*}\right) \\
1^{1} \mathrm{~A}_{2}^{\prime}\left(\pi \rightarrow \pi^{*}\right) \\
2^{1} \mathrm{~A}_{1}^{\prime}\left(\pi \rightarrow \pi^{*}\right) \\
2^{1} \mathrm{E}^{\prime \prime}\left(n \rightarrow \pi^{*}\right)\end{array}$ & $\begin{array}{l}4.70 \\
4.80 \\
4.77 \\
5.82 \\
7.52 \\
8.04\end{array}$ & $\begin{array}{l}4.60 \\
4.71 \\
4.68 \\
5.80 \\
7.26 \\
7.97\end{array}$ & $\begin{array}{l}4.81 \\
4.83 \\
4.87 \\
5.76 \\
7.44 \\
7.95\end{array}$ & $\begin{array}{l}4.74 \\
4.79 \\
4.81 \\
5.77 \\
7.21 \\
7.93\end{array}$ & & \\
\hline
\end{tabular}

Continued on Next Page... 
Table 1 - Continued

\begin{tabular}{|c|c|c|c|c|c|c|c|}
\hline \multirow[t]{2}{*}{ Molecule } & \multirow[t]{2}{*}{ State } & \multicolumn{2}{|r|}{$\mathrm{CC} 2$} & \multicolumn{2}{|c|}{$\operatorname{CCSDR}(3)$} & \multicolumn{2}{|r|}{$\mathrm{CC} 3$} \\
\hline & & TZVP & aug-cc-pVTZ & TZVP & aug-cc-pVTZ & TZVP & aug-cc-pVTZ \\
\hline \multirow{14}{*}{$s$-tetrazine } & $1^{1} \mathrm{E}^{\prime}\left(\pi \rightarrow \pi^{*}\right)$ & 8.06 & 7.88 & 8.07 & 7.87 & & \\
\hline & ${ }^{1} \mathrm{~B}_{3 u}\left(n \rightarrow \pi^{*}\right)$ & $\begin{array}{l}2.47 \\
367\end{array}$ & $\begin{array}{l}2.39 \\
361\end{array}$ & $\begin{array}{l}2.61 \\
3.88\end{array}$ & 2.56 & 2.53 & 2.46 \\
\hline & $1^{1} \mathrm{~B}_{1 g}\left(n \rightarrow \pi^{*}\right)$ & 5.10 & $\begin{array}{l}5.01 \\
5.00\end{array}$ & $\begin{array}{l}5.00 \\
5.15\end{array}$ & $\begin{array}{l}5.00 \\
5.08\end{array}$ & 4.97 & 4.87 \\
\hline & $1^{1} \mathrm{~B}_{2 u}\left(\pi \rightarrow \pi^{*}\right)$ & 5.20 & 5.16 & 5.20 & 5.18 & 5.12 & 5.08 \\
\hline & $1^{1} \mathrm{~B}_{2 g}\left(n \rightarrow \pi^{*}\right)$ & 5.53 & 5.45 & 5.51 & 5.47 & 5.34 & 5.28 \\
\hline & $2^{1} \mathrm{~A}_{u}\left(n \rightarrow \pi^{*}\right)$ & 5.50 & 5.40 & 5.56 & 5.49 & & \\
\hline & $2^{1} \mathrm{~B}_{2 g}\left(n \rightarrow \pi^{*}\right)$ & 6.32 & 6.23 & 6.43 & 6.40 & 6.23 & 6.16 \\
\hline & $2^{1} \mathrm{~B}_{1 g}\left(n \rightarrow \pi^{*}\right)$ & 6.91 & 6.82 & 6.98 & 6.94 & 6.87 & 6.80 \\
\hline & $3^{1} \mathrm{~B}_{1 g}\left(n \rightarrow \pi^{*}\right)$ & 7.64 & 7.42 & 7.60 & 7.64 & & \\
\hline & $2^{1} \mathrm{~B}_{3 u}\left(n \rightarrow \pi^{*}\right)$ & 6.70 & 6.61 & 6.77 & 6.72 & 6.67 & 6.60 \\
\hline & $1^{1} \mathrm{~B}_{1 u}\left(\pi \rightarrow \pi^{*}\right)$ & 7.60 & 7.51 & 7.54 & 7.27 & 7.45 & 7.18 \\
\hline & $2^{1} \mathrm{~B}_{1 u}\left(\pi \rightarrow \pi^{*}\right)$ & 7.75 & 7.65 & 7.83 & 7.65 & 7.79 & 7.59 \\
\hline & $2^{1} \mathrm{~B}_{2 u}\left(\pi \rightarrow \pi^{*}\right)$ & 8.65 & 8.45 & 8.58 & 8.40 & & \\
\hline & $2^{1} \mathrm{~B}_{3 g}\left(\pi \rightarrow \pi^{*}\right)$ & 8.97 & 8.85 & 8.86 & 8.90 & & \\
\hline \multirow[t]{2}{*}{ Formaldehyde } & $1^{1} \mathrm{~A}_{2}\left(n \rightarrow \pi^{*}\right)$ & 4.09 & 4.00 & 3.94 & 3.89 & 3.95 & 3.88 \\
\hline & $1^{1} \mathrm{~B}_{1}\left(\sigma \rightarrow \pi^{*}\right)$ & 9.35 & 9.19 & 9.19 & 9.06 & 9.18 & 9.05 \\
\hline \multirow[t]{3}{*}{ Acetone } & $1^{1} \mathrm{~A}_{2}\left(n \rightarrow \pi^{*}\right)$ & 4.52 & 4.45 & 4.39 & 4.39 & 4.40 & 4.38 \\
\hline & $1^{1} \mathrm{~B}_{1}\left(\sigma \rightarrow \pi^{*}\right)$ & 9.29 & 9.11 & 9.17 & 9.04 & & \\
\hline & $2^{1} \mathrm{~A}_{1}\left(\pi \rightarrow \pi^{*}\right)$ & 9.74 & 9.31 & 9.66 & 8.92 & 9.65 & 8.90 \\
\hline$p$-Benzoquinone & $1^{1} \mathrm{~A}_{u}\left(n \rightarrow \pi^{*}\right)$ & 2.92 & 2.88 & 3.01 & 3.02 & & \\
\hline
\end{tabular}

Continued on Next Page... 
Table 1 - Continued

\begin{tabular}{|c|c|c|c|c|c|c|c|}
\hline \multirow[t]{2}{*}{ Molecule } & \multirow[t]{2}{*}{ State } & \multicolumn{2}{|r|}{$\mathrm{CC} 2$} & \multicolumn{2}{|c|}{$\operatorname{CCSDR}(3)$} & \multicolumn{2}{|r|}{$\mathrm{CC} 3$} \\
\hline & & TZVP & aug-cc-pVTZ & TZVP & aug-cc-pVTZ & TZVP & aug-cc-pVTZ \\
\hline$\gamma$ & $\begin{array}{l}1^{1} \mathrm{~B}_{1 g}\left(n \rightarrow \pi^{*}\right) \\
1^{1} \mathrm{~B}_{3 g}\left(\pi \rightarrow \pi^{*}\right) \\
1^{1} \mathrm{~B}_{1 u}\left(\pi \rightarrow \pi^{*}\right) \\
1^{1} \mathrm{~B}_{3 u}\left(n \rightarrow \pi^{*}\right) \\
2^{1} \mathrm{~B}_{3 g}\left(\pi \rightarrow \pi^{*}\right) \\
2^{1} \mathrm{~B}_{1 u}\left(\pi \rightarrow \pi^{*}\right)\end{array}$ & $\begin{array}{l}2.81 \\
4.69 \\
5.59 \\
5.69 \\
7.36 \\
8.31\end{array}$ & $\begin{array}{l}2.76 \\
4.53 \\
5.46 \\
5.55 \\
7.17 \\
8.10\end{array}$ & $\begin{array}{l}2.90 \\
4.69 \\
5.65 \\
6.09 \\
7.36 \\
8.10\end{array}$ & $\begin{array}{l}2.89 \\
4.54 \\
5.51 \\
5.98 \\
7.25 \\
7.90\end{array}$ & & \\
\hline Formamide & $1^{1} \mathrm{~A}^{\prime \prime}\left(n \rightarrow \pi^{*}\right)$ & 5.76 & 5.59 & 5.65 & 5.56 & 5.65 & 5.55 \\
\hline Acetamide & $\begin{array}{l}1^{1} \mathrm{~A}^{\prime \prime}\left(n \rightarrow \pi^{*}\right) \\
2^{1} \mathrm{~A}^{\prime}\left(\pi \rightarrow \pi^{*}\right) \\
3^{1} \mathrm{~A}^{\prime}\left(\pi \rightarrow \pi^{*}\right)\end{array}$ & $\begin{array}{c}5.77 \\
7.66 \\
10.71\end{array}$ & $\begin{array}{c}5.61 \\
7.23 \\
10.21\end{array}$ & $\begin{array}{c}5.69 \\
7.69 \\
10.56\end{array}$ & $\begin{array}{l}5.62 \\
7.16 \\
9.72\end{array}$ & & \\
\hline Propanamide & $\begin{array}{l}1^{1} \mathrm{~A}^{\prime \prime}\left(n \rightarrow \pi^{*}\right) \\
2^{1} \mathrm{~A}^{\prime}\left(\pi \rightarrow \pi^{*}\right) \\
3^{1} \mathrm{~A}^{\prime}\left(\pi \rightarrow \pi^{*}\right)\end{array}$ & $\begin{array}{c}5.78 \\
7.56 \\
10.33\end{array}$ & $\begin{array}{l}5.62 \\
7.16 \\
9.71\end{array}$ & $\begin{array}{l}5.71 \\
7.64\end{array}$ & $\begin{array}{l}5.64 \\
7.12\end{array}$ & & \\
\hline Cytosine & $\begin{array}{l}2^{1} \mathrm{~A}^{\prime}\left(\pi \rightarrow \pi^{*}\right) \\
1^{1} \mathrm{~A}^{\prime \prime}\left(n \rightarrow \pi^{*}\right) \\
2^{1} \mathrm{~A}^{\prime \prime}\left(n \rightarrow \pi^{*}\right) \\
3^{1} \mathrm{~A}^{\prime}\left(\pi \rightarrow \pi^{*}\right) \\
4^{1} \mathrm{~A}^{\prime}\left(\pi \rightarrow \pi^{*}\right) \\
5^{1} \mathrm{~A}^{\prime}\left(\pi \rightarrow \pi^{*}\right)\end{array}$ & $\begin{array}{l}4.80 \\
5.43 \\
5.01 \\
5.71 \\
6.65 \\
6.94\end{array}$ & $\begin{array}{l}4.69 \\
4.91 \\
5.33 \\
5.56 \\
6.29 \\
6.62\end{array}$ & & & & \\
\hline Thymine & $\begin{array}{l}1^{1} \mathrm{~A}^{\prime \prime}\left(n \rightarrow \pi^{*}\right) \\
2^{1} \mathrm{~A}^{\prime}\left(\pi \rightarrow \pi^{*}\right)\end{array}$ & $\begin{array}{l}4.94 \\
5.39\end{array}$ & $\begin{array}{l}4.83 \\
5.19\end{array}$ & & & & \\
\hline
\end{tabular}


Table 1 - Continued

\begin{tabular}{|c|c|c|c|c|c|c|c|}
\hline \multirow[t]{2}{*}{ Molecule } & \multirow[t]{2}{*}{ State } & \multicolumn{2}{|r|}{$\mathrm{CC} 2$} & \multicolumn{2}{|c|}{$\operatorname{CCSDR}(3)$} & \multicolumn{2}{|r|}{ CC3 } \\
\hline & & TZVP & aug-cc-pVTZ & TZVP & aug-cc-pVTZ & TZVP & aug-cc-pVTZ \\
\hline & $\begin{array}{l}3^{1} \mathrm{~A}^{\prime}\left(\pi \rightarrow \pi^{*}\right) \\
2^{1} \mathrm{~A}^{\prime \prime}\left(n \rightarrow \pi^{*}\right) \\
4^{1} \mathrm{~A}^{\prime}\left(\pi \rightarrow \pi^{*}\right) \\
4^{1} \mathrm{~A}^{\prime \prime}\left(n \rightarrow \pi^{*}\right) \\
5^{1} \mathrm{~A}^{\prime \prime}\left(n \rightarrow \pi^{*}\right) \\
5^{1} \mathrm{~A}^{\prime}\left(\pi \rightarrow \pi^{*}\right)\end{array}$ & $\begin{array}{l}6.46 \\
6.33 \\
6.80 \\
6.73 \\
7.18 \\
7.71\end{array}$ & $\begin{array}{l}6.26 \\
6.16 \\
6.50 \\
6.55 \\
7.00 \\
7.47\end{array}$ & & & & \\
\hline Uracil & $\begin{array}{l}1^{1} \mathrm{~A}^{\prime \prime}\left(n \rightarrow \pi^{*}\right) \\
2^{1} \mathrm{~A}^{\prime}\left(\pi \rightarrow \pi^{*}\right) \\
3^{1} \mathrm{~A}^{\prime}\left(\pi \rightarrow \pi^{*}\right) \\
2^{1} \mathrm{~A}^{\prime \prime}\left(n \rightarrow \pi^{*}\right) \\
3^{1} \mathrm{~A}^{\prime \prime}\left(n \rightarrow \pi^{*}\right) \\
4^{1} \mathrm{~A}^{\prime}\left(\pi \rightarrow \pi^{*}\right) \\
5^{1} \mathrm{~A}^{\prime \prime}\left(n \rightarrow \pi^{*}\right) \\
5^{1} \mathrm{~A}^{\prime}\left(\pi \rightarrow \pi^{*}\right)\end{array}$ & $\begin{array}{l}4.91 \\
5.52 \\
6.43 \\
6.73 \\
6.26 \\
6.96 \\
7.12 \\
7.66\end{array}$ & $\begin{array}{l}4.81 \\
5.33 \\
6.24 \\
6.09 \\
6.55 \\
6.66 \\
6.95 \\
7.48\end{array}$ & & & & \\
\hline Adenine & $\begin{array}{l}2^{1} \mathrm{~A}^{\prime}\left(\pi \rightarrow \pi^{*}\right) \\
3^{1} \mathrm{~A}^{\prime}\left(\pi \rightarrow \pi^{*}\right) \\
1^{1} \mathrm{~A}^{\prime \prime}\left(n \rightarrow \pi^{*}\right) \\
2^{1} \mathrm{~A}^{\prime \prime}\left(n \rightarrow \pi^{*}\right)\end{array}$ & $\begin{array}{l}5.28 \\
5.42 \\
5.27 \\
5.91\end{array}$ & $\begin{array}{l}5.20 \\
5.20 \\
5.13 \\
5.74\end{array}$ & & & & \\
\hline
\end{tabular}

${ }^{a}$ Results with the TZVP basis set from ref. [1]

${ }^{b}$ Results with the aug-cc-pVTZ basis set from this work. 


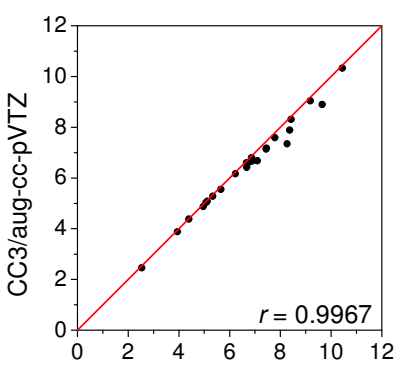

Figure 1. Correlation plots for the vertical excitation $/$ TZVVP

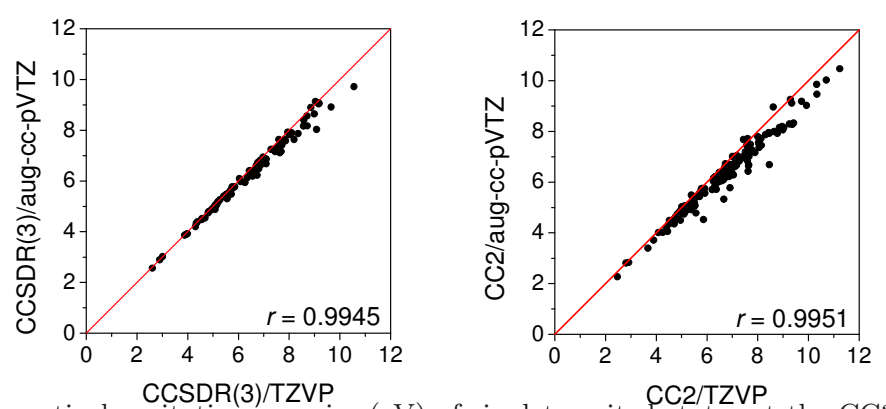
CCSDR(3), and CC2 levels: aug-cc-pVTZ vs. TZVP results.

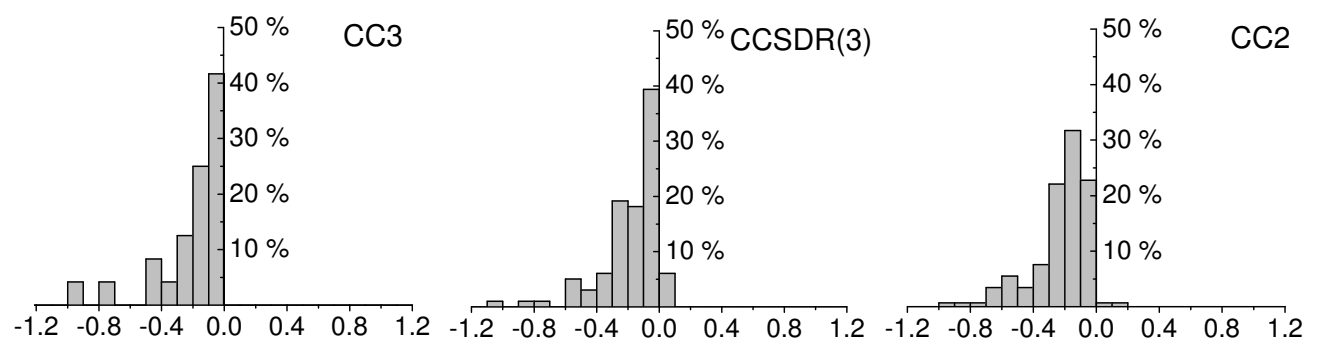

Figure 2. Histograms (in \%) of the deviations between aug-cc-pVTZ and TZVP vertical excitation energies $(\mathrm{eV})$ of singlet excited states at the CC3, CCSDR(3), and CC2 levels.

\section{Results}

In Table 1 we present the results for singlet excited states obtained with the CC2, CCSDR(3) and CC3 methods and the aug-cc-pVTZ basis set. Those obtained previously with the TZVP basis set $[1,3]$ are also listed for comparison. Some higher-lying states of the original benchmark set (e.g. in formamide, formaldehyde, and naphthalene) are not included here due to problems in identifying these states when using the aug-cc-pVTZ basis set. Within an acceptable amount of compute time, we could afford to calculate a total of 22 states with the CC3 method and 99 states with the CCSDR(3) method. In both cases, the triples contributions scale formally as $N^{7}$ with the number of orbitals $N$. But while CC3 has an iterative triples contribution, $\operatorname{CCSDR}(3)$ is based on a pseudoperturbation theory expansion of the CC3 eigenvalue problem and thus includes essentially only a non-iterative triples correction which is added to the CCSD excitation energy. The efficient parallel implementation of the RI-CC2 method in the TURBOMOLE program allowed us to compute all the singlet excited states from the original benchmark set at the $\mathrm{CC} 2$ level.

In Figure 1 the correlation between the aug-cc-pVTZ and TZVP results is shown graphically for the three coupled cluster methods, while Figure 2 presents histograms for the deviations of the aug-cc-pVTZ from the TZVP results. The corresponding statistical data are given in Table 2 .

Upon inspection of the numerical results and the histograms in Figure 2, one immediately sees a systematic lowering of the calculated excitation energies when going from the TZVP to the larger aug-cc-pVTZ basis, for each of the three coupled cluster methods. There are only three states at the CC2 level $\left(4^{1} \mathrm{~A}^{\prime}\right.$ in imidazole, $2^{1} \mathrm{~A}^{\prime \prime}$ in cytosine, and $3^{1} \mathrm{~A}^{\prime \prime}$ in uracil) and six at the CCSDR $(3)$ level $\left(2^{1} \mathrm{~A}_{g}\right.$ in allE-hexatriene, $2^{1} \mathrm{~A}_{g}$ in pyrazine, $1^{1} \mathrm{~A}_{2}^{\prime}$ in $s$-triazine, $3^{1} \mathrm{~B}_{1 g}$ and $2^{1} \mathrm{~B}_{3 g}$ in $s$-tetrazine and $1^{1} \mathrm{~A}_{u}$ in $p$-benzoquinone) which have a higher energy with the aug-cc-pVTZ basis. These are mostly states with rather low single excitation weights, $\% R_{1}$, in the CC3/TZVP calculations [3]. The correlation (Figure 1) between the results with 
Table 2. Deviations in the vertical excitation energies (eV) of singlet excited states: aug-cc-pVTZ vs. TZVP results ${ }^{\mathrm{a}}$.

\begin{tabular}{lrrrr}
\hline & CC2 & CC2 $^{\mathrm{b}}$ & CCSDR $(3)$ & CC3 \\
\hline Count $^{\mathrm{c}}$ & 143 & 99 & 99 & 22 \\
Mean $_{\text {Abs. Mean }}$ & -0.22 & -0.22 & -0.18 & -0.18 \\
Std. Dev. & 0.23 & 0.22 & 0.18 & 0.18 \\
Maximum (-) & 0.29 & 0.28 & 0.26 & 0.25 \\
\hline
\end{tabular}

a TZVP results from Refs. [1, 3].

b Same subset of states as in $\operatorname{CCSDR}(3)$.

c Total number of considered states.

the two basis sets is almost perfect, with correlation coefficients of 0.9951, 0.9945, and 0.9967 for CC2, CCSDR(3), and CC3, respectively. Only for high-lying states with energies above $8 \mathrm{eV}$ there are a few outliers. The largest one concerns the $3{ }^{1} \mathrm{~B}_{2}$ state in pyridine at the $\mathrm{CC} 2(-1.34 \mathrm{eV})$ and $\operatorname{CCSDR}(3)(-1.05 \mathrm{eV})$ levels, which also has a low single excitation weight, $\% R_{1}$, in the CC3/TZVP calculations [3]. The second largest outliers are found for the $4^{1} \mathrm{~A}_{1}$ state in cyclopentadiene at the $\mathrm{CC} 2$ level $(-0.67 \mathrm{eV})$ and for the $2^{1} \mathrm{~A}_{1}$ state in acetone at the CCSDR $(3)$ and $\mathrm{CC} 3$ levels. For most other states there is close agreement between the aug-cc-pVTZ and TZVP results (see e.g. the $1^{1} \mathrm{~B}_{2 u}$ states in benzene and $s$-tetrazine with deviations of less than $0.05 \mathrm{eV}$ for all three methods).

There is another particular outlier in pyrrole that requires some comment. A previous extensive coupled cluster study of pyrrole [32] found significant valenceRydberg mixing in the three lowest excited ${ }^{1} \mathrm{~B}_{2}$ states showing "similar diffuseness and oscillator strengths". We also see considerable mixing in our coupled cluster calculations: for example, both CC2/aug-cc-pVTZ and CCSDR(3)/aug-cc-pVTZ yield two strongly mixed ${ }^{1} \mathrm{~B}_{2}$ states at $6.25 / 6.85 \mathrm{eV}$ and $6.23 / 6.81 \mathrm{eV}$, respectively. According to our standard assignment criteria, the more valence-like state occurs at higher energy for $\mathrm{CC} 2$ and at lower energy for CCSDR(3), by a small margin in each case, and the corresponding entries in Table 1 are thus 6.85 and $6.23 \mathrm{eV}$, respectively. At face value, this would seem to indicate a large discrepancy between the CC2 and CCSDR(3) results which are in reality quite similar (see above). We have refrained from imposing correlations between the assignments of separate calculations, to be as unbiased as possible, even though this will artificially deteriorate the statistical results to some extent. Our general conclusions are however not affected by this choice.

The mean and absolute mean deviations in Table 2 are of essentially the same magnitude (about $0.2 \mathrm{eV}$ ) for all three coupled cluster methods. This confirms that the basis set effects are very systematic. Looking at the finer details in Table 2, we note that the basis set dependence is slightly more pronounced for $\mathrm{CC} 2$ than for CCSDR(3) and CC3, both for the full set of CC2 results as well as for the subset of states that is shared between CC2 and CCSDR(3). Comparing CCSDR(3) and CC3, the statistical data in Table 2 as well as the individual numerical results indicate an essentially identical basis set dependence of the computed vertical excitation energies. This suggests an incremental scheme where expensive CC3 calculations that may only be feasible with a smaller basis set (such as TZVP) are augmented with a basis set correction obtained at the cheaper CC2 or CCSDR(3) level.

For the 22 states where CC3/aug-cc-pVTZ results are available, this correction scheme has been tested, with statistical results listed in Table 3. For the estimates obtained from the CC3/TZVP results plus the CCSDR(3) correction, the agreement with the CC3/aug-cc-pVTZ results is almost perfect, with negligible mean 
Table 3. Deviations in the vertical excitation energies $(\mathrm{eV})$ of singlet excited states: CC3/TZVP-based estimates with CC2 and CCSDR(3) basis set corrections vs. CC3/augcc-pVTZ results. See text.

\begin{tabular}{lcc}
\hline & CC3 with CC2 correction $^{\mathrm{a}}$ & CC3 with CCSDR(3) correction $^{\mathrm{b}}$ \\
\hline Count $^{\mathrm{c}}$ & 22 & 22 \\
Mean & -0.02 & 0.01 \\
Abs. Mean & 0.08 & 0.02 \\
Std. Dev. & 0.15 & 0.02 \\
Maximum (-) & 0.42 & 0.03 \\
Maximum (+) & 0.32 & 0.04 \\
\hline a Estimated CC3/aug-cc-pVTZ $=$ CC3/TZVP + CC2/aug-cc-pVTZ - CC2/TZVP. \\
b Estimated CC3/aug-cc-pVTZ $=$ CC3/TZVP + CCSDR(3)/aug-cc-pVTZ - \\
CCSDR(3)/TZVP.
\end{tabular}

Table 4. Deviation of CC2 and CCSDR(3) excitation energies (eV) of singlet excited states with respect to CC3 results obtained with the same basis set ${ }^{\mathrm{a}}$.

\begin{tabular}{lcccccc}
\hline & \multicolumn{7}{c}{ Method } \\
\cline { 2 - 7 } & \multicolumn{7}{c}{ CC2 } & \multicolumn{2}{c}{ CCSDR(3) } \\
\cline { 2 - 7 } & TZVP $^{\mathrm{b}}$ & TZVP $^{\mathrm{c}}$ & aug-cc-pVTZ & TZVP $^{\text {d }}$ & TZVP & aug-cc-pVTZ \\
\hline Count $^{\mathrm{f}}$ & 118 & 22 & 22 & 118 & 22 & 22 \\
Mean & 0.13 & 0.14 & 0.11 & 0.09 & 0.07 & 0.08 \\
Abs. Mean & 0.16 & 0.15 & 0.12 & 0.09 & 0.07 & 0.08 \\
Std. Dev. & 0.25 & 0.25 & 0.17 & 0.14 & 0.11 & 0.12 \\
Maximum (+) & 0.95 & 0.86 & 0.43 & 0.52 & 0.28 & 0.25 \\
\hline
\end{tabular}

a Columns labeled with TZVP have CC3/TZVP results [1] as reference data. Columns labeled with aug-cc-pVTZ have the present CC3/aug-cc-pVTZ results as reference data.

b Reference [1].

c Subset of singlet states from Reference [1], in order to compare directly with the present aug-cc-pVTZ results.

d Reference [3].

e Subset of singlet states from Reference [3], in order to compare directly with the present aug-cc-pVTZ results.

f Total number of considered states. Some data has been discarded whose assignment was considered unreliable.

and absolute mean deviations of 0.01 and $0.02 \mathrm{eV}$, respectively, and a maximum deviation of only $0.04 \mathrm{eV}$. The $\mathrm{CC} 2$ correction performs not quite so well: the mean and absolute mean deviations are still quite low (-0.02 and $0.08 \mathrm{eV}$, respectively), but there are outliers for states with a low CC3/TZVP single excitation weight (maximum deviation of $-0.42 \mathrm{eV}$ for $2^{1} \mathrm{~A}_{g}$ of butadiene and $1^{1} \mathrm{E}_{2 g}$ of benzene, $\% R_{1}$ below $70 \%)$.

In Table 4 we compare the performance of CC2 and CCSDR(3) relative to CC3, both for the TZVP $[1,3]$ and aug-cc-pVTZ basis sets. Table 5 provides an analogous comparison between CC2 and CCSDR(3), again for both basis sets. In each case, the given deviations refer to excitation energies calculated with a lower-level vs. a higher-level coupled cluster method (using the same basis). The mean and absolute deviations between the CCSDR(3) and CC3 results are essentially of the same magnitude $(0.08 \pm 0.01 \mathrm{eV})$ for both basis sets. In the case of $\mathrm{CC} 2$, the mean absolute deviations from the CC3 and $\operatorname{CCSDR}(3)$ results are slightly smaller for the augcc-pVTZ basis $(0.12$ and $0.10 \mathrm{eV})$ than for the TZVP basis $(0.16$ and $0.11 \mathrm{eV})$ so that the higher-level results are reproduced slightly better with the larger basis.

Using the CC2 method we have also computed vertical excitation energies for triplet excited states as well as one-electron properties for singlet excited states (oscillator strengths and dipole moments). The correlation between the aug-cc- 
Table 5. Deviation of CC2 excitation energies (eV) of singlet excited states with respect to CCSDR(3) results obtained with the same basis set ${ }^{\mathrm{a}}$.

\begin{tabular}{lccc}
\hline & TZVP $^{\mathrm{b}}$ & TZVP $^{\mathrm{c}}$ & aug-cc-pVTZ \\
\hline Count $^{\mathrm{d}}$ & 118 & 99 & 99 \\
Mean & 0.04 & 0.03 & 0.00 \\
Abs. Mean & 0.11 & 0.11 & 0.10 \\
Std. Dev. & 0.16 & 0.15 & 0.14 \\
Maximum (+) & 0.68 & 0.68 & 0.62 \\
\hline
\end{tabular}

a Columns labeled with TZVP have CCSDR(3)/TZVP results [3] as reference data. Columns labeled with augcc-pVTZ have the present CCSDR(3)/aug-cc-pVTZ results as reference data.

b CCSDR(3) results from reference [3] and CC2 results from reference [1].

c Subset of singlet states of the CCSDR(3) results from reference [3] and $\mathrm{CC} 2$ results from reference [1], in order to compare directly with the present aug-cc-pVTZ results.

d Total number of considered states.

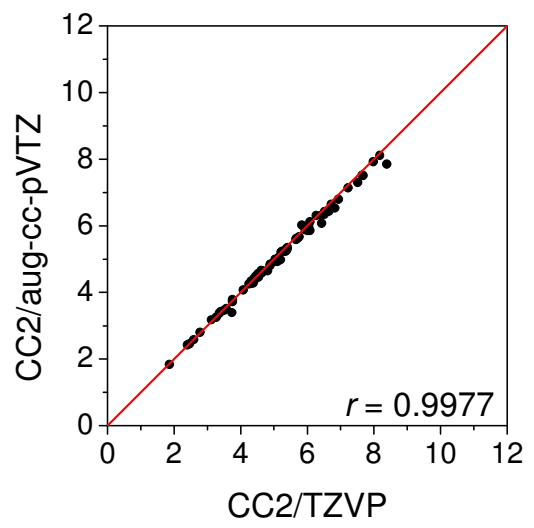

Figure 3. Correlation plots for the vertical excitation energies of triplet excited states: Basis set effects for $\mathrm{CC} 2$.

pVTZ and TZVP results is shown in Figures 3 and 4. The corresponding statistical data for the differences between the aug-cc-pVTZ and TZVP results are given in Table 6. For the vertical triplet excitation energies, the CC2 results for the two basis sets exhibit very small mean and absolute mean deviations of -0.08 and 0.10 $\mathrm{eV}$, respectively, as well as a very large correlation coefficient of 0.9977 , which confirms the high quality of the previous CC2/TZVP results for the triplet states. Obviously the vertical excitation energies for the triplets are even less basis set dependent than those for the singlet excited states.

The situation is less clear-cut for one-electron properties, i.e., for the oscillator strengths and dipole moments of the singlet excited states, which are apparently affected more strongly by the addition of further diffuse and polarization functions in the basis set. While extension of the basis set leads to a slight systematic lowering in the calculated vertical excitation energies, the one-electron properties change more randomly, although there is also a general overall trend towards lower absolute values (see Figure 4). Stronger variations may be caused by changes in the composition of states when further diffuse and/or polarization functions are included: Two states which are composed of $+/-$ combinations of configuration state functions and thus give rise to bright/dark states could mix differently upon basis set extension and then evolve into two states with moderate intensity. Generally 

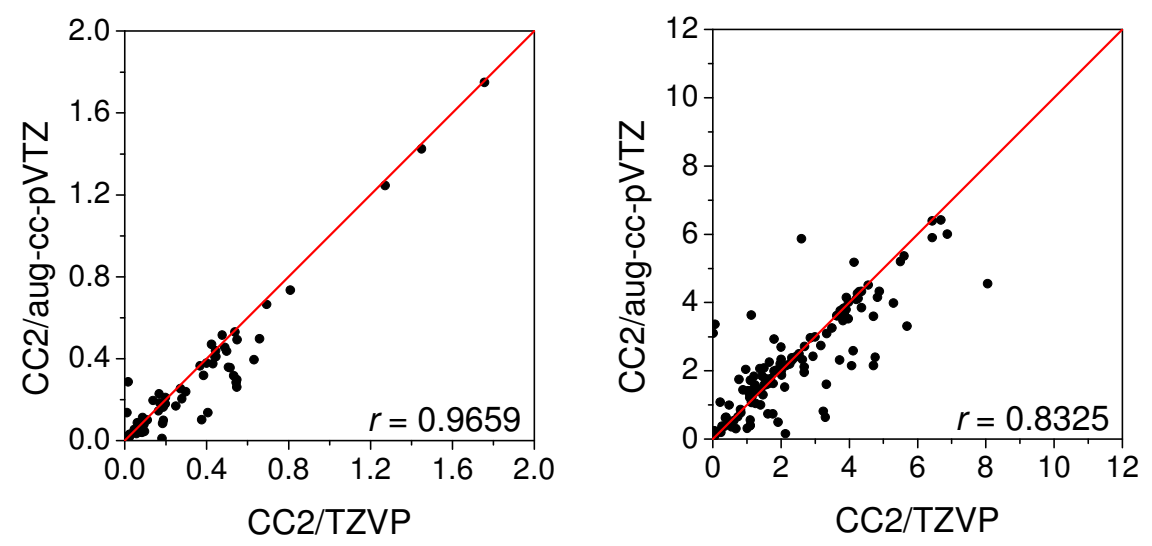

Figure 4. Correlation plots for (left) oscillator strengths and (right) dipole moments of singlet excited states: Basis set effects for CC2. Table 6. Deviations between the CC2/aug-cc-pVTZ and CC2/TZVP results for the vertical
excitation energies (eV) of singlet and triplet excited states and for the oscillator strengths
and dipole moments (D) of singlet excited states: Statistics for all 28 benchmark molecules.

\begin{tabular}{lcccc}
\hline & \multicolumn{4}{c}{ CC2/aug-cc-pVTZ } \\
\cline { 2 - 4 } & Singlet states & Triplet states & Osc. strength & Dipole moment \\
\hline Count $^{\mathrm{a}}$ & 143 & 71 & 95 & 127 \\
Mean & -0.22 & -0.08 & -0.032 & -0.14 \\
Abs. Mean & 0.23 & 0.10 & 0.047 & 0.57 \\
Std. Dev. & 0.29 & 0.14 & 0.088 & 0.97 \\
Maximum (-) & 1.34 & 0.54 & 0.287 & 3.51 \\
\hline a Total number of considered states. Some data has been discarded whose assignment \\
was considered unreliable.
\end{tabular}

speaking, the oscillator strengths and excited-state dipole moments depend more than the energies on the proper description of the excited-state wavefunctions, and they should thus be more susceptible to basis set effects (especially in the case of diffuse high-lying states). The largest changes in the oscillator strengths indeed occur for the high-lying states of cytosine $\left(4 \mathrm{~A}^{\prime}\right.$ : -0.238$)$ and uracil $\left(5 \mathrm{~A}^{\prime}:-0.287\right)$ where the intensities of these bright states are lowered considerably. For the dipole moments, the largest changes are found for the high-lying states of cytosine $\left(4 \mathrm{~A}^{\prime}\right.$ : $-2.38 \mathrm{D}$ and $5 \mathrm{~A}^{\prime}$ : $\left.-3.51 \mathrm{D}\right)$. Turning to the statistics again, the correlation coefficients are 0.9659 for the oscillator strengths and 0.8325 for excited-state dipole moments (see Figure 4), which are still reasonably large, but significantly smaller than those for the vertical excitation energies. In summary, the differences between the CC2/aug-cc-pVTZ and CC2/TZVP results for the one-electron properties are still appreciable, and convergence with regard to basis set extension thus appears to be slower for these properties than for the excitation energies.

\section{Conclusions}

We have revisited a benchmark set of electronically excited states. Vertical excitation energies to singlet excited states were calculated with the CC2, CCSDR(3) and CC3 coupled cluster linear response methods, using the same geometries as in previous studies, but with the augmented correlation-consistent aug-cc-pVTZ basis instead of the TZVP basis. A total of 143 states were covered at the CC2 level. Due to the high computational demands of $\operatorname{CCSDR}(3)$ and in particular CC3, a smaller number of states were investigated with these methods, i.e., 99 with $\operatorname{CCSDR}(3)$ 
and 22 with CC3.

Inspection of the individual numerical results and statistical evaluations for the aug-cc-pVTZ and TZVP data show that the basis set effects on the calculated singlet excitation energies are rather uniform, for each of the three coupled cluster methods investigated. There is a systematic lowering of the computed energies upon basis set extension, of typically about $0.2 \mathrm{eV}$ on average. This provides some justification for an incremental scheme where $\mathrm{CC} 3$ results obtained with a moderate basis are augmented by applying a basis set correction determined with a less costly coupled cluster method such as CC2 or $\operatorname{CCSDR}(3)$.

In the case of triplet excited states, the $\mathrm{CC} 2$ vertical excitation energies are even less basis set dependent than in the singlet case, since going from TZVP to aug-cc-pVTZ causes only a very minor lowering of typically $0.1 \mathrm{eV}$. By contrast, the changes in the $\mathrm{CC} 2$ oscillator strengths and dipole moments for singlet excited states are less systematic and sometimes rather random. Hence, further convergence studies are desirable for these one-electron properties.

To conclude, some of the calculated vertical excitation energies, in particular those to high-lying singlet states, are significantly lowered by the inclusion of additional diffuse and polarization functions in the aug-cc-pVTZ basis set (compared to TZVP), and further changes may be expected upon addition of molecule-centered diffuse functions for states with significant valence-Rydberg mixing. However, in an overall assessment of the present results, the effects of basis set extension on the vertical excitation energies of the chosen benchmark set are rather minor. Therefore, our previous conclusions on the performance of the coupled cluster methods CC2, CCSDR(3), and CC3 in excited-state studies remain valid $[1,3]$.

\section{Acknowledgements}

This work was supported by the Deutsche Forschungsgemeinschaft (SFB 663, project C4). M.R.S.J. gladly acknowledges support by the Deutscher Akademischer Austauschdienst (DAAD). S.P.A.S. acknowledges support from the Danish Center for Scientific Computing (DCSC) and from the Danish Natural Science Research Council/The Danish Councils for Independent Research. We thank Prof. Christoph Hättig for helpful discussions.

\section{References}

[1]M. Schreiber, M.R. Silva-Junior, S.P.A. Sauer and W. Thiel, Benchmarks for electronically excited states: CASPT2, CC2, CCSD and CC3, J. Chem. Phys. 128, 134110 (2008).

[2]M.R. Silva-Junior, M. Schreiber, S.P.A. Sauer and W. Thiel, Benchmarks for electronically excited states: Time-dependent density functional theory and density functional theory based multireference configuration interaction, J. Chem. Phys. 129, 104103 (2008).

[3]S.P.A. Sauer, M. Schreiber, M.R. Silva-Junior and W. Thiel, Benchmarks for electronically excited states: A comparison of noniterative and iterative triples corrections in linear response coupled cluster methods: CCSDR(3) versus CC3, J. Chem. Theory Comput. 5, 555-564 (2009).

[4]L. Goerigk, J. Moellmann and S. Grimme, Computation of accurate excitation energies for large organic molecules with double-hybrid density functionals, Phys. Chem. Chem. Phys. 11, 4611 (2009).

[5]D. Jacquemin, V. Wathelet, E.A. Perpete and C. Adamo, Extensive TD-DFT Benchmark: SingletExcited States of Organic Molecules, J. Chem. Theory Comput. 5, 2420-2435 (2009).

[6]A. Schäfer, H. Horn and R. Ahlrichs, Fully optimized contracted Gaussian basis sets for atoms Li to Kr, J. Chem. Phys. 97, 2571-2577 (1992).

[7]K.L. Bak, H. Koch, J. Oddershede, O. Christiansen and S.P.A. Sauer, Atomic integral driven second order polarization propagator calculations of the excitation spectra of naphthalene and anthracene, J. Chem. Phys. 112, 4173-4185 (2000).

[8]H.H. Falden, K.R. Falster-Hansen, K.L. Bak, S. Rettrup, and S.P.A. Sauer, Benchmarking second order methods for the calculation of vertical electronic excitation energies: Valence and Rydberg states in polycyclic aromatic hydrocarbons, J. Phys. Chem. A 113, 11995-12012 (2009).

[9]T.H. Dunning, Jr., Gaussian basis sets for use in correlated molecular calculations. I. The atoms boron through neon and hydrogen, J. Chem. Phys. 90, 1007-1023 (1989). 
[10]R.A. Kendall, T.H. Dunning, Jr. and R.J. Harrison, Electron affinities of first row atoms revisited systematic basis sets and wave functions, J. Chem. Phys. 96, 6796-6806 (1992).

[11]O. Christiansen, H. Koch and P. Jørgensen, Response functions in the CC3 iterative triple excitation model, J. Chem. Phys. 103, 7429-7441 (1995).

[12] O. Christiansen, H. Koch, A. Halkier, P. Jørgensen, T. Helgaker and A. Sánchez de Merís, Large-scale calculations of excitation energies in coupled cluster theory: The singlet excited states of benzene, J. Chem. Phys. 105, 6921-6939 (1996).

[13]K. Hald, C. Hättig and P. Jørgensen, Triplet excitation energies in the coupled cluster singles and doubles model using an explicit triplet spin coupled excitation space, J. Chem. Phys. 113, 7765-7772 (2000).

[14]A. Öhrn and O. Christiansen, Electronic excitation energies of pyrimidine studied using coupled cluster response theory, Phys. Chem. Chem. Phys. 3, 730-740 (2001).

[15]A. Osted, J. Kongsted and O. Christiansen, Theoretical Study of the Electronic Gas-Phase Spectrum of Glycine, Alanine, and Related Amines and Carboxylic Acids, J. Phys. Chem. A 109, 1430-1440 (2005).

[16] O. Christiansen, H. Koch and P. Jørgensen, Perturbative triple excitation corrections to coupled cluster singles and doubles excitation energies, J. Chem. Phys. 105, 1451-1459 (1996).

[17] O. Christiansen, H. Koch, P. Jørgensen and J. Olsen, Excitation Energies of $\mathrm{H}_{2} \mathrm{O}, \mathrm{N}_{2}$ and $\mathrm{C}_{2}$ in Full Configuration Interaction and Coupled Cluster Theory, Chem. Phys. Letters 256, 185-194 (1996).

[18] H. Koch, O. Christiansen, P. Jørgensen, A.M.S. de Merás and T. Helgaker, The CC3 model: An iterative coupled cluster approach including connected triples, J. Chem. Phys. 106, 1808-1818 (1997).

[19] K. Hald, C. Hättig, J. Olsen and P. Jørgensen, CC3 triplet excitation energies using an explicit spin coupled excitation space, J. Chem. Phys. 115, 3545-3552 (2001).

[20]Dalton, a molecular electronic structure program, Release 2.0 (2005) <http://www.kjemi.uio.no/software/dalton/dalton.html>.

[21] O. Christiansen, H. Koch and P. Jørgensen, The second-order approximate coupled cluster singles and doubles model CC2, Chem. Phys. Letters 243, 409-418 (1995).

[22] K. Hald, C. Hättig, D.L. Yeager and P. Jørgensen, Linear response CC2 triplet excitation energies, Chem. Phys. Letters 328, 291-301 (2000).

[23]C. Hättig and F. Weigend, CC2 excitation energy calculations on large molecules using the resolution of the identity approximation, J. Chem. Phys. 113, 5154-5161 (2000).

[24] C. Hättig and K. Hald, Implementation of RI-CC2 triplet excitation energies with an application to trans-azobenzene, Phys. Chem. Chem. Phys. 4, 2111-2118 (2002).

[25]C. Hättig, A. Köhn and K. Hald, First-order properties for triplet excited states in the approximated coupled cluster model CC2 using an explicitly spin coupled basis, J. Chem. Phys. 116, 5401-5410 (2002).

[26]C. Hättig and A. Köhn, Transition moments and excited-state first-order properties in the coupledcluster model CC2 using the resolution-of-the-identity approximation, J. Chem. Phys. 117, 6939-6951 (2002).

[27]TURBOMOLE V5.10 2008, a development of University of Karlsruhe and Forschungszentrum Karlsruhe GmbH, 1989-2007, TURBOMOLE GmbH, since 2007; available from <http://www.turbomole.com>.

[28] O. Vahtras, J.E. Amlöf and M.W. Feyereisen, Integral approximations for LCAO-SCF calculations, Chem. Phys. Letters 213, 514-518 (1993).

[29] M.W. Feyereisen, G. Fitzgerald and A. Komornicki, Use of approximate integrals in ab initio theory. An application in MP2 energy calculations, Chem. Phys. Letters 208, 359-363 (1993).

[30]F. Weigend, A. Köhn and C. Hättig, Efficient use of the correlation consistent basis sets in resolution of the identity MP2 calculations, J. Chem. Phys. 116, 3175-3183 (2002).

[31] C. Hättig, Optimization of auxiliary basis sets for RI-MP2 and RI-CC2 calculations: Core-valence and quintuple- $\zeta$ basis sets for $\mathrm{H}$ to Ar and QZVPP basis sets for Li to Kr, Phys. Chem. Chem. Phys. 7, 59-66 (2005).

[32] O. Christiansen, J. Gauss, J. F. Stanton and P. Jørgensen, The electronic spectrum of pyrrole, J. Chem. Phys. 111, 525-537 (1999). 
Appendix A. CC2 results for vertical excitation energies of triplet excited states.

Table A1.: Vertical excitation energies $(\mathrm{eV})$ of triplet excited states from $\mathrm{CC} 2$ calculations with the $\mathrm{TZVP}^{a}$ and aug-cc$\mathrm{pVTZ}^{b}$ basis sets.

\begin{tabular}{|c|c|c|c|}
\hline \multirow[t]{2}{*}{ Molecule } & \multirow[t]{2}{*}{ State } & \multicolumn{2}{|r|}{$\mathrm{CC} 2$} \\
\hline & & TZVP & aug-cc-pVTZ \\
\hline Ethene & $1^{3} \mathrm{~B}_{1 u}\left(\pi \rightarrow \pi^{*}\right)$ & 4.52 & 4.56 \\
\hline E-Butadiene & $\begin{array}{l}1^{3} \mathrm{~B}_{u}\left(\pi \rightarrow \pi^{*}\right) \\
1^{3} \mathrm{~A}_{g}\left(\pi \rightarrow \pi^{*}\right)\end{array}$ & $\begin{array}{l}3.40 \\
5.25\end{array}$ & $\begin{array}{l}3.43 \\
5.24\end{array}$ \\
\hline all-E-Hexatriene & $\begin{array}{l}1^{3} \mathrm{~B}_{u}\left(\pi \rightarrow \pi^{*}\right) \\
1^{3} \mathrm{~A}_{g}\left(\pi \rightarrow \pi^{*}\right)\end{array}$ & $\begin{array}{l}2.78 \\
4.40\end{array}$ & $\begin{array}{l}2.80 \\
4.42\end{array}$ \\
\hline all-E-Octatetraene & $\begin{array}{l}1^{3} \mathrm{~B}_{u}\left(\pi \rightarrow \pi^{*}\right) \\
1^{3} \mathrm{~A}_{g}\left(\pi \rightarrow \pi^{*}\right)\end{array}$ & $\begin{array}{l}2.40 \\
3.76\end{array}$ & $\begin{array}{l}2.42 \\
3.78\end{array}$ \\
\hline Cyclopropene & $\begin{array}{l}1^{3} \mathrm{~B}_{2}\left(\pi \rightarrow \pi^{*}\right) \\
1^{3} \mathrm{~B}_{1}\left(\sigma \rightarrow \pi^{*}\right)\end{array}$ & $\begin{array}{l}4.44 \\
6.65\end{array}$ & $\begin{array}{l}4.40 \\
6.44\end{array}$ \\
\hline Cyclopentadiene & $\begin{array}{l}1^{3} \mathrm{~B}_{2}\left(\pi \rightarrow \pi^{*}\right) \\
1^{3} \mathrm{~A}_{1}\left(\pi \rightarrow \pi^{*}\right)\end{array}$ & $\begin{array}{l}3.36 \\
5.22\end{array}$ & $\begin{array}{l}3.37 \\
5.22\end{array}$ \\
\hline Norbornadiene & $\begin{array}{l}1^{3} \mathrm{~A}_{2}\left(\pi \rightarrow \pi^{*}\right) \\
1^{3} \mathrm{~B}_{2}\left(\pi \rightarrow \pi^{*}\right)\end{array}$ & $\begin{array}{l}3.76 \\
4.25\end{array}$ & $\begin{array}{l}3.72 \\
4.25\end{array}$ \\
\hline Benzene & $\begin{array}{l}1^{3} \mathrm{~B}_{1 u}\left(\pi \rightarrow \pi^{*}\right) \\
1^{3} \mathrm{E}_{1 u}\left(\pi \rightarrow \pi^{*}\right) \\
1^{3} \mathrm{~B}_{2 u}\left(\pi \rightarrow \pi^{*}\right) \\
1^{3} \mathrm{E}_{2 g}\left(\pi \rightarrow \pi^{*}\right)\end{array}$ & $\begin{array}{l}4.31 \\
5.14 \\
6.08 \\
7.99\end{array}$ & $\begin{array}{l}4.33 \\
5.05 \\
5.86 \\
7.92\end{array}$ \\
\hline Naphthalene & $\begin{array}{l}1^{3} \mathrm{~B}_{2 u}\left(\pi \rightarrow \pi^{*}\right) \\
1^{3} \mathrm{~B}_{3 u}\left(\pi \rightarrow \pi^{*}\right) \\
1^{3} \mathrm{~B}_{1 g}\left(\pi \rightarrow \pi^{*}\right) \\
2^{3} \mathrm{~B}_{2 u}\left(\pi \rightarrow \pi^{*}\right) \\
2^{3} \mathrm{~B}_{3 u}\left(\pi \rightarrow \pi^{*}\right) \\
1^{3} \mathrm{~A}_{g}\left(\pi \rightarrow \pi^{*}\right) \\
2^{3} \mathrm{~B}_{1 g}\left(\pi \rightarrow \pi^{*}\right) \\
2^{3} \mathrm{~A}_{g}\left(\pi \rightarrow \pi^{*}\right) \\
3^{3} \mathrm{~A}_{g}\left(\pi \rightarrow \pi^{*}\right) \\
3^{3} \mathrm{~B}_{1 g}\left(\pi \rightarrow \pi^{*}\right)\end{array}$ & $\begin{array}{l}3.27 \\
4.38 \\
4.64 \\
4.88 \\
5.11 \\
5.76 \\
6.44 \\
6.83 \\
6.94 \\
7.23\end{array}$ & $\begin{array}{l}3.25 \\
4.28 \\
4.59 \\
4.81 \\
4.93 \\
5.67 \\
6.07 \\
6.53 \\
6.80 \\
7.14\end{array}$ \\
\hline Furan & $\begin{array}{l}1^{3} \mathrm{~B}_{2}\left(\pi \rightarrow \pi^{*}\right) \\
1^{3} \mathrm{~A}_{1}\left(\pi \rightarrow \pi^{*}\right)\end{array}$ & $\begin{array}{l}4.38 \\
5.67\end{array}$ & $\begin{array}{l}4.33 \\
5.61\end{array}$ \\
\hline Pyrrole & $\begin{array}{l}1^{3} \mathrm{~B}_{2}\left(\pi \rightarrow \pi^{*}\right) \\
1^{3} \mathrm{~A}_{1}\left(\pi \rightarrow \pi^{*}\right)\end{array}$ & $\begin{array}{l}4.68 \\
5.72\end{array}$ & $\begin{array}{l}4.64 \\
5.63\end{array}$ \\
\hline Imidazole & $\begin{array}{l}1^{3} \mathrm{~A}^{\prime}\left(\pi \rightarrow \pi^{*}\right) \\
2^{3} \mathrm{~A}^{\prime}\left(\pi \rightarrow \pi^{*}\right) \\
1^{3} \mathrm{~A}^{\prime \prime}\left(n \rightarrow \pi^{*}\right) \\
3^{3} \mathrm{~A}^{\prime}\left(\pi \rightarrow \pi^{*}\right)\end{array}$ & $\begin{array}{l}4.89 \\
6.01 \\
6.44 \\
6.74\end{array}$ & $\begin{array}{l}4.85 \\
5.86 \\
6.32 \\
6.57\end{array}$ \\
\hline
\end{tabular}

Continued on Next Page... 
Taylor EG Francis and I.T. Consultant

Table A1 - Continued

\begin{tabular}{|c|c|c|c|}
\hline \multirow[t]{2}{*}{ Molecule } & \multirow[t]{2}{*}{ State } & \multicolumn{2}{|r|}{$\mathrm{CC} 2$} \\
\hline & & TZVP & aug-cc-pVTZ \\
\hline & $\begin{array}{l}4^{3} \mathrm{~A}^{\prime}\left(\pi \rightarrow \pi^{*}\right) \\
2^{3} \mathrm{~A}^{\prime \prime}\left(n \rightarrow \pi^{*}\right)\end{array}$ & $\begin{array}{l}7.68 \\
7.52\end{array}$ & $\begin{array}{l}7.51 \\
7.30\end{array}$ \\
\hline Pyridine & $\begin{array}{l}1^{3} \mathrm{~A}_{1}\left(\pi \rightarrow \pi^{*}\right) \\
1^{3} \mathrm{~B}_{1}\left(n \rightarrow \pi^{*}\right) \\
1^{3} \mathrm{~B}_{2}\left(\pi \rightarrow \pi^{*}\right) \\
2^{3} \mathrm{~A}_{1}\left(\pi \rightarrow \pi^{*}\right) \\
1^{3} \mathrm{~A}_{2}\left(n \rightarrow \pi^{*}\right) \\
2^{3} \mathrm{~B}_{2}\left(\pi \rightarrow \pi^{*}\right) \\
3^{3} \mathrm{~B}_{2}\left(\pi \rightarrow \pi^{*}\right) \\
3^{3} \mathrm{~A}_{1}\left(\pi \rightarrow \pi^{*}\right)\end{array}$ & $\begin{array}{l}4.46 \\
4.54 \\
5.07 \\
5.33 \\
5.35 \\
6.52 \\
8.39 \\
8.18\end{array}$ & $\begin{array}{l}4.48 \\
4.46 \\
4.93 \\
5.24 \\
5.24 \\
6.34 \\
7.85 \\
8.11 \\
\end{array}$ \\
\hline s-Tetrazine & $\begin{array}{l}1^{3} \mathrm{~B}_{3 u}\left(n \rightarrow \pi^{*}\right) \\
1^{3} \mathrm{~A}_{u}\left(n \rightarrow \pi^{*}\right) \\
1^{3} \mathrm{~B}_{1 g}\left(n \rightarrow \pi^{*}\right) \\
1^{3} \mathrm{~B}_{1 u}\left(\pi \rightarrow \pi^{*}\right) \\
1^{3} \mathrm{~B}_{2 u}\left(\pi \rightarrow \pi^{*}\right) \\
1^{3} \mathrm{~B}_{2 g}\left(n \rightarrow \pi^{*}\right) \\
2^{3} \mathrm{~A}_{u}\left(n \rightarrow \pi^{*}\right) \\
1^{3} \mathrm{~B}_{3 g}(n, n \rightarrow \\
\left.\pi^{*}, \pi^{*}\right) \\
2^{3} \mathrm{~B}_{1 u}\left(\pi \rightarrow \pi^{*}\right) \\
2^{3} \mathrm{~B}_{2 g}\left(n \rightarrow \pi^{*}\right) \\
2^{3} \mathrm{~B}_{1 g}\left(n \rightarrow \pi^{*}\right) \\
2^{3} \mathrm{~B}_{3 u}\left(n \rightarrow \pi^{*}\right) \\
2^{3} \mathrm{~B}_{2 u}\left(\pi \rightarrow \pi^{*}\right)\end{array}$ & $\begin{array}{l}1.86 \\
3.43 \\
4.30 \\
4.62 \\
4.81 \\
5.03 \\
5.05\end{array}$ & $\begin{array}{l}1.83 \\
3.39 \\
4.27 \\
4.66 \\
4.65 \\
4.99 \\
4.98\end{array}$ \\
\hline Formaldehyde & $\begin{array}{l}1^{3} \mathrm{~A}_{2}\left(\pi \rightarrow \pi^{*}\right) \\
1^{3} \mathrm{~A}_{1}\left(\pi \rightarrow \pi^{*}\right)\end{array}$ & $\begin{array}{l}3.57 \\
6.08\end{array}$ & $\begin{array}{l}3.52 \\
6.12\end{array}$ \\
\hline Acetone & $\begin{array}{l}1^{3} \mathrm{~A}_{2}\left(n \rightarrow \pi^{*}\right) \\
1^{3} \mathrm{~A}_{1}\left(\pi \rightarrow \pi^{*}\right)\end{array}$ & $\begin{array}{l}4.08 \\
6.27\end{array}$ & $\begin{array}{l}4.07 \\
6.31\end{array}$ \\
\hline$p$-Benzoquinone & $\begin{array}{l}1^{3} \mathrm{~B}_{1 g}\left(n \rightarrow \pi^{*}\right) \\
1^{3} \mathrm{~A}_{u}\left(n \rightarrow \pi^{*}\right) \\
1^{3} \mathrm{~B}_{1 u}\left(\pi \rightarrow \pi^{*}\right) \\
1^{3} \mathrm{~B}_{3 g}\left(\pi \rightarrow \pi^{*}\right)\end{array}$ & $\begin{array}{l}2.47 \\
2.59 \\
3.12 \\
3.50\end{array}$ & $\begin{array}{l}2.46 \\
2.58 \\
3.18 \\
3.46\end{array}$ \\
\hline Formamide & $\begin{array}{l}1^{3} \mathrm{~A}^{\prime \prime}\left(n \rightarrow \pi^{*}\right) \\
1^{3} \mathrm{~A}^{\prime}\left(\pi \rightarrow \pi^{*}\right)\end{array}$ & $\begin{array}{l}5.39 \\
5.94\end{array}$ & $\begin{array}{l}5.27 \\
5.88\end{array}$ \\
\hline Acetamide & $\begin{array}{l}1^{3} \mathrm{~A}^{\prime \prime}\left(n \rightarrow \pi^{*}\right) \\
1^{3} \mathrm{~A}^{\prime}\left(\pi \rightarrow \pi^{*}\right)\end{array}$ & $\begin{array}{l}5.42 \\
6.06\end{array}$ & $\begin{array}{l}5.33 \\
5.88\end{array}$ \\
\hline Propanamide & $\begin{array}{l}1^{3} \mathrm{~A}^{\prime \prime}\left(n \rightarrow \pi^{*}\right) \\
1^{3} \mathrm{~A}^{\prime}\left(\pi \rightarrow \pi^{*}\right)\end{array}$ & $\begin{array}{l}5.44 \\
6.07\end{array}$ & $\begin{array}{l}5.35 \\
6.02\end{array}$ \\
\hline
\end{tabular}

${ }^{a}$ Results with the TZVP basis set from ref. [1]

${ }^{b}$ Results with the aug-cc-pVTZ basis set from this work. \\ Molecular Physics}


Appendix B. CC2 results for oscillator strengths and dipole moments of singlet excited states.

Table B1.: Oscillator strengths (in dipole length representation) for optically allowed transitions from $\mathrm{CC} 2$ calculations $^{a}$.

\begin{tabular}{|c|c|c|c|}
\hline \multirow[t]{2}{*}{ Molecule } & \multirow[t]{2}{*}{ State } & \multicolumn{2}{|r|}{$\mathrm{CC} 2$} \\
\hline & & $\mathrm{TZVP}^{b}$ & aug-cc-pVTZ ${ }^{c}$ \\
\hline Ethene & $1^{1} \mathrm{~B}_{1 u}\left(\pi \rightarrow \pi^{*}\right)$ & 0.431 & 0.375 \\
\hline E-Butadiene & $1^{1} \mathrm{~B}_{u}\left(\pi \rightarrow \pi^{*}\right)$ & 0.809 & 0.734 \\
\hline all-E-Hexatriene & $1^{1} \mathrm{~B}_{u}\left(\pi \rightarrow \pi^{*}\right)$ & 1.272 & 1.246 \\
\hline all-E-Octatetraene & $1^{1} \mathrm{~B}_{u}\left(\pi \rightarrow \pi^{*}\right)$ & 1.757 & 1.749 \\
\hline Cyclopropene & $\begin{array}{l}1^{1} \mathrm{~B}_{2}\left(\pi \rightarrow \pi^{*}\right) \\
1^{1} \mathrm{~B}_{1}\left(\sigma \rightarrow \pi^{*}\right)\end{array}$ & $\begin{array}{l}0.086 \\
0.001\end{array}$ & $\begin{array}{l}0.072 \\
0.000\end{array}$ \\
\hline Cyclopentadiene & $\begin{array}{l}2^{1} \mathrm{~A}_{1}\left(\pi \rightarrow \pi^{*}\right) \\
3^{1} \mathrm{~A}_{1}\left(\pi \rightarrow \pi^{*}\right) \\
1^{1} \mathrm{~B}_{2}\left(\pi \rightarrow \pi^{*}\right)\end{array}$ & $\begin{array}{l}0.011 \\
0.658 \\
0.110\end{array}$ & $\begin{array}{l}0.001 \\
0.497 \\
0.100\end{array}$ \\
\hline Norbornadiene & $\begin{array}{l}1^{1} \mathrm{~B}_{2}\left(\pi \rightarrow \pi^{*}\right) \\
2^{1} \mathrm{~B}_{2}\left(\pi \rightarrow \pi^{*}\right)\end{array}$ & $\begin{array}{l}0.023 \\
0.185\end{array}$ & $\begin{array}{l}0.020 \\
0.083\end{array}$ \\
\hline Benzene & $1^{1} \mathrm{E}_{1 u}\left(\pi \rightarrow \pi^{*}\right)$ & 0.694 & 0.664 \\
\hline Naphthalene & $\begin{array}{l}1^{1} \mathrm{~B}_{2 u}\left(\pi \rightarrow \pi^{*}\right) \\
2^{1} \mathrm{~B}_{2 u}\left(\pi \rightarrow \pi^{*}\right) \\
3^{1} \mathrm{~B}_{2 u}\left(\pi \rightarrow \pi^{*}\right) \\
2^{1} \mathrm{~B}_{3 u}\left(\pi \rightarrow \pi^{*}\right) \\
3^{1} \mathrm{~B}_{3 u}\left(\pi \rightarrow \pi^{*}\right)\end{array}$ & $\begin{array}{l}0.094 \\
0.272 \\
0.548 \\
1.450 \\
0.010\end{array}$ & $\begin{array}{l}0.078 \\
0.253 \\
0.297 \\
1.424 \\
0.015\end{array}$ \\
\hline Furan & $\begin{array}{l}2^{1} \mathrm{~A}_{1}\left(\pi \rightarrow \pi^{*}\right) \\
3^{1} \mathrm{~A}_{1}\left(\pi \rightarrow \pi^{*}\right) \\
1^{1} \mathrm{~B}_{2}\left(\pi \rightarrow \pi^{*}\right)\end{array}$ & $\begin{array}{l}0.003 \\
0.506 \\
0.172\end{array}$ & $\begin{array}{l}0.000 \\
0.358 \\
0.184\end{array}$ \\
\hline Pyrrole & $\begin{array}{l}2^{1} \mathrm{~A}_{1}\left(\pi \rightarrow \pi^{*}\right) \\
3^{1} \mathrm{~A}_{1}\left(\pi \rightarrow \pi^{*}\right) \\
1^{1} \mathrm{~B}_{2}\left(\pi \rightarrow \pi^{*}\right)\end{array}$ & $\begin{array}{l}0.006 \\
0.532 \\
0.182\end{array}$ & $\begin{array}{l}0.001 \\
0.317 \\
0.011\end{array}$ \\
\hline Imidazole & $\begin{array}{l}2^{1} \mathrm{~A}^{\prime}\left(\pi \rightarrow \pi^{*}\right) \\
3^{1} \mathrm{~A}^{\prime}\left(\pi \rightarrow \pi^{*}\right) \\
4^{1} \mathrm{~A}^{\prime}\left(\pi \rightarrow \pi^{*}\right) \\
1^{1} \mathrm{~A}^{\prime \prime}\left(n \rightarrow \pi^{*}\right) \\
2^{1} \mathrm{~A}^{\prime \prime}\left(n \rightarrow \pi^{*}\right)\end{array}$ & $\begin{array}{l}0.088 \\
0.085 \\
0.406 \\
0.003 \\
0.006\end{array}$ & $\begin{array}{l}0.112 \\
0.040 \\
0.136 \\
0.002 \\
0.002\end{array}$ \\
\hline Pyridine & $\begin{array}{l}2^{1} \mathrm{~A}_{1}\left(\pi \rightarrow \pi^{*}\right) \\
3^{1} \mathrm{~A}_{1}\left(\pi \rightarrow \pi^{*}\right) \\
1^{1} \mathrm{~B}_{2}\left(\pi \rightarrow \pi^{*}\right) \\
2^{1} \mathrm{~B}_{2}\left(\pi \rightarrow \pi^{*}\right) \\
1^{1} \mathrm{~B}_{1}\left(n \rightarrow \pi^{*}\right)\end{array}$ & $\begin{array}{l}0.021 \\
0.498 \\
0.025 \\
0.549 \\
0.005\end{array}$ & $\begin{array}{l}0.014 \\
0.436 \\
0.032 \\
0.493 \\
0.005\end{array}$ \\
\hline Pyrazine & $\begin{array}{l}1^{1} \mathrm{~B}_{1 u}\left(\pi \rightarrow \pi^{*}\right) \\
2^{1} \mathrm{~B}_{1 u}\left(\pi \rightarrow \pi^{*}\right) \\
1^{1} \mathrm{~B}_{2 u}\left(\pi \rightarrow \pi^{*}\right) \\
2^{1} \mathrm{~B}_{2 u}\left(\pi \rightarrow \pi^{*}\right)\end{array}$ & $\begin{array}{l}0.096 \\
0.424 \\
0.070 \\
0.400\end{array}$ & $\begin{array}{l}0.045 \\
0.470 \\
0.084 \\
0.378\end{array}$ \\
\hline
\end{tabular}

Continued on Next Page... 
Table B1 - Continued

\begin{tabular}{|c|c|c|c|}
\hline \multirow[t]{2}{*}{ Molecule } & \multirow[t]{2}{*}{ State } & \multicolumn{2}{|r|}{$\mathrm{CC} 2$} \\
\hline & & $\mathrm{TZVP}^{b}$ & aug-cc-pVTZc \\
\hline \multirow{6}{*}{ Pyrimidine } & $1^{1} \mathrm{~B}_{3 u}\left(n \rightarrow \pi^{*}\right)$ & 0.007 & 0.001 \\
\hline & $2^{1} \mathrm{~A}_{1}\left(\pi \rightarrow \pi^{*}\right)$ & 0.062 & 0.086 \\
\hline & $3^{1} \mathrm{~A}_{1}\left(\pi \rightarrow \pi^{*}\right)$ & 0.446 & 0.410 \\
\hline & $1^{1} \mathrm{~B}_{2}\left(\pi \rightarrow \pi^{*}\right)$ & 0.023 & 0.029 \\
\hline & $2^{1} \mathrm{~B}_{2}\left(\pi \rightarrow \pi^{*}\right)$ & 0.476 & 0.515 \\
\hline & $1^{1} \mathrm{~B}_{1}\left(n \rightarrow \pi^{*}\right)$ & 0.006 & 0.005 \\
\hline \multirow[t]{6}{*}{ Pyridazine } & $2^{1} \mathrm{~A}_{1}\left(\pi \rightarrow \pi^{*}\right)$ & 0.014 & 0.017 \\
\hline & $3^{1} \mathrm{~A}_{1}\left(\pi \rightarrow \pi^{*}\right)$ & 0.444 & 0.438 \\
\hline & $1^{1} \mathrm{~B}_{2}\left(\pi \rightarrow \pi^{*}\right)$ & 0.009 & 0.003 \\
\hline & $2^{1} \mathrm{~B}_{2}\left(\pi \rightarrow \pi^{*}\right)$ & 0.489 & 0.455 \\
\hline & $1^{1} \mathrm{~B}_{1}\left(n \rightarrow \pi^{*}\right)$ & 0.006 & 0.005 \\
\hline & $2^{1} \mathrm{~B}_{1}\left(n \rightarrow \pi^{*}\right)$ & 0.005 & 0.004 \\
\hline \multirow[t]{2}{*}{$s$-Triazine } & $1^{1} \mathrm{E}^{\prime}\left(\pi \rightarrow \pi^{*}\right)$ & 0.441 & 0.410 \\
\hline & $1^{1} \mathrm{~A}_{2}^{\prime \prime}\left(n \rightarrow \pi^{*}\right)$ & 0.017 & 0.015 \\
\hline \multirow[t]{6}{*}{ s-Tetrazine } & $1^{1} \mathrm{~B}_{1 u}\left(\pi \rightarrow \pi^{*}\right)$ & 0.017 & 0.286 \\
\hline & $2^{1} \mathrm{~B}_{1 u}\left(\pi \rightarrow \pi^{*}\right)$ & 0.376 & 0.102 \\
\hline & $1^{1} \mathrm{~B}_{2 u}\left(\pi \rightarrow \pi^{*}\right)$ & 0.046 & 0.054 \\
\hline & $2^{1} \mathrm{~B}_{2 u}\left(\pi \rightarrow \pi^{*}\right)$ & 0.368 & 0.364 \\
\hline & $1^{1} \mathrm{~B}_{3 u}\left(n \rightarrow \pi^{*}\right)$ & 0.007 & 0.006 \\
\hline & $1^{1} \mathrm{~B}_{3 u}\left(n \rightarrow \pi^{*}\right)$ & 0.011 & 0.011 \\
\hline Formaldehyde & $1^{1} \mathrm{~B}_{1}\left(\sigma \rightarrow \pi^{*}\right)$ & 0.079 & 0.001 \\
\hline Acetone & $2^{1} \mathrm{~A}_{1}\left(\pi \rightarrow \pi^{*}\right)$ & 0.298 & 0.238 \\
\hline \multirow[t]{3}{*}{$p$-Benzoquinone } & $1^{1} \mathrm{~B}_{1 u}\left(\pi \rightarrow \pi^{*}\right)$ & 0.538 & 0.530 \\
\hline & $2^{1} \mathrm{~B}_{1 u}\left(\pi \rightarrow \pi^{*}\right)$ & 0.544 & 0.283 \\
\hline & $1^{1} \mathrm{~B}_{3 u}\left(n \rightarrow \pi^{*}\right)$ & 0.000 & 0.001 \\
\hline Formamide & $1^{1} \mathrm{~A}^{\prime \prime}\left(n \rightarrow \pi^{*}\right)$ & 0.001 & 0.001 \\
\hline \multirow[t]{3}{*}{ Acetamide } & $2^{1} \mathrm{~A}^{\prime}\left(\pi \rightarrow \pi^{*}\right)$ & 0.199 & 0.210 \\
\hline & $3^{1} \mathrm{~A}^{\prime}\left(\pi \rightarrow \pi^{*}\right)$ & 0.279 & 0.204 \\
\hline & $1^{1} \mathrm{~A}^{\prime \prime}\left(n \rightarrow \pi^{*}\right)$ & 0.001 & 0.000 \\
\hline \multirow[t]{2}{*}{ Propanamide } & $2^{1} \mathrm{~A}^{\prime}\left(\pi \rightarrow \pi^{*}\right)$ & 0.138 & 0.196 \\
\hline & $3^{1} \mathrm{~A}^{\prime}\left(\pi \rightarrow \pi^{*}\right)$ & 0.189 & 0.099 \\
\hline \multirow[t]{6}{*}{ Cytosine } & $2^{1} \mathrm{~A}^{\prime}\left(\pi \rightarrow \pi^{*}\right)$ & 0.049 & 0.050 \\
\hline & $3^{1} \mathrm{~A}^{\prime}\left(\pi \rightarrow \pi^{*}\right)$ & 0.165 & 0.144 \\
\hline & $4^{1} \mathrm{~A}^{\prime}\left(\pi \rightarrow \pi^{*}\right)$ & 0.632 & 0.395 \\
\hline & $5^{1} \mathrm{~A}^{\prime}\left(\pi \rightarrow \pi^{*}\right)$ & 0.168 & 0.228 \\
\hline & $1^{1} \mathrm{~A}^{\prime \prime}\left(n \rightarrow \pi^{*}\right)$ & 0.001 & 0.001 \\
\hline & $2^{1} \mathrm{~A}^{\prime \prime}\left(n \rightarrow \pi^{*}\right)$ & 0.002 & 0.001 \\
\hline \multirow[t]{5}{*}{ Thymine } & $2^{1} \mathrm{~A}^{\prime}\left(\pi \rightarrow \pi^{*}\right)$ & 0.197 & 0.179 \\
\hline & $3^{1} \mathrm{~A}^{\prime}\left(\pi \rightarrow \pi^{*}\right)$ & 0.080 & 0.041 \\
\hline & $4^{1} \mathrm{~A}^{\prime}\left(\pi \rightarrow \pi^{*}\right)$ & 0.250 & 0.168 \\
\hline & $5^{1} \mathrm{~A}^{\prime}\left(\pi \rightarrow \pi^{*}\right)$ & 0.515 & 0.356 \\
\hline & $3^{1} \mathrm{~A}^{\prime \prime}\left(n \rightarrow \pi^{*}\right)$ & 0.000 & 0.001 \\
\hline
\end{tabular}

Continued on Next Page... 
Table B1 - Continued

\begin{tabular}{llcc}
\hline \hline Molecule & State & \multicolumn{2}{c}{$\mathrm{CC} 2$} \\
\cline { 3 - 4 } & & TZVP $^{b}$ & aug-cc-pVTZ \\
\hline Uracil & $2^{1} \mathrm{~A}^{\prime}\left(\pi \rightarrow \pi^{*}\right)$ & 0.197 & 0.178 \\
& $3^{1} \mathrm{~A}^{\prime}\left(\pi \rightarrow \pi^{*}\right)$ & 0.058 & 0.034 \\
& $4^{1} \mathrm{~A}^{\prime}\left(\pi \rightarrow \pi^{*}\right)$ & 0.188 & 0.163 \\
& $5^{1} \mathrm{~A}^{\prime}\left(\pi \rightarrow \pi^{*}\right)$ & 0.547 & 0.260 \\
& $3^{1} \mathrm{~A}^{\prime \prime}\left(n \rightarrow \pi^{*}\right)$ & 0.000 & 0.001 \\
\hline \hline
\end{tabular}

${ }^{a}$ Only values above 0.001 are listed.

${ }^{b}$ Results with the TZVP basis set from ref. [1]

${ }^{c}$ Results with the aug-cc-pVTZ basis set from this work. 
Table B2.: Dipole moments (in Debye) of singlet excited states from CC2 calculations.

\begin{tabular}{|c|c|c|c|}
\hline \multirow[t]{2}{*}{ Molecule } & \multirow[t]{2}{*}{ State } & \multicolumn{2}{|r|}{$\mathrm{CC} 2$} \\
\hline & & $\mathrm{TZVP}^{a}$ & aug-cc-pVTZ ${ }^{b}$ \\
\hline \multirow[t]{5}{*}{ Cyclopropene } & Ground State & 0.45 & 0.44 \\
\hline & $1^{1} \mathrm{~B}_{2}\left(\pi \rightarrow \pi^{*}\right)$ & 1.26 & 1.04 \\
\hline & $1^{1} \mathrm{~B}_{1}\left(\sigma \rightarrow \pi^{*}\right)$ & 1.62 & 0.73 \\
\hline & $1^{3} \mathrm{~B}_{2}\left(\pi \rightarrow \pi^{*}\right)$ & 0.35 & 0.37 \\
\hline & $1^{3} \mathrm{~B}_{1}\left(\sigma \rightarrow \pi^{*}\right)$ & 1.77 & 1.62 \\
\hline \multirow[t]{6}{*}{ Cyclopentadiene } & Ground State & 0.46 & 0.45 \\
\hline & $2^{1} \mathrm{~A}_{1}\left(\pi \rightarrow \pi^{*}\right)$ & 0.68 & 0.30 \\
\hline & $3^{1} \mathrm{~A}_{1}\left(\pi \rightarrow \pi^{*}\right)$ & 1.13 & 3.63 \\
\hline & $1^{1} \mathrm{~B}_{2}\left(\pi \rightarrow \pi^{*}\right)$ & 0.24 & 0.20 \\
\hline & $1^{3} \mathrm{~A}_{1}\left(\pi \rightarrow \pi^{*}\right)$ & 0.27 & 0.37 \\
\hline & $1^{3} \mathrm{~B}_{2}\left(\pi \rightarrow \pi^{*}\right)$ & 0.05 & 0.18 \\
\hline \multirow{7}{*}{ Norbornadiene } & Ground State & 0.06 & 0.09 \\
\hline & $1^{1} \mathrm{~A}_{2}\left(\pi \rightarrow \pi^{*}\right)$ & 0.22 & 1.08 \\
\hline & $2^{1} \mathrm{~A}_{2}\left(\pi \rightarrow \pi^{*}\right)$ & 0.55 & 0.36 \\
\hline & ${ }^{1} \mathrm{~B}_{2}\left(\pi \rightarrow \pi^{*}\right)$ & 0.89 & 1.44 \\
\hline & $2^{1} \mathrm{~B}_{2}\left(\pi \rightarrow \pi^{*}\right)$ & 0.07 & 3.36 \\
\hline & $1^{3} \mathrm{~A}_{2}\left(\pi \rightarrow \pi^{*}\right)$ & 0.05 & 0.24 \\
\hline & $1^{3} \mathrm{~B}_{2}\left(\pi \rightarrow \pi^{*}\right)$ & 0.18 & 0.23 \\
\hline \multirow[t]{6}{*}{ Furan } & Ground State & 0.62 & 1.87 \\
\hline & $2^{1} \mathrm{~A}_{1}\left(\pi \rightarrow \pi^{*}\right)$ & 0.83 & 0.77 \\
\hline & $3^{1} \mathrm{~A}_{1}\left(\pi \rightarrow \pi^{*}\right)$ & 0.01 & 3.10 \\
\hline & $1^{1} \mathrm{~B}_{2}\left(\pi \rightarrow \pi^{*}\right)$ & 0.77 & 1.74 \\
\hline & $1^{3} \mathrm{~A}_{1}\left(\pi \rightarrow \pi^{*}\right)$ & 0.74 & 0.65 \\
\hline & $1^{3} \mathrm{~B}_{2}\left(\pi \rightarrow \pi^{*}\right)$ & 1.14 & 1.06 \\
\hline \multirow[t]{6}{*}{ Pyrrole } & Ground State & 2.02 & 1.87 \\
\hline & $2^{1} \mathrm{~A}_{1}\left(\pi \rightarrow \pi^{*}\right)$ & 1.47 & 1.29 \\
\hline & $3^{1} \mathrm{~A}_{1}\left(\pi \rightarrow \pi^{*}\right)$ & 2.60 & 5.87 \\
\hline & $1^{1} \mathrm{~B}_{2}\left(\pi \rightarrow \pi^{*}\right)$ & 1.92 & 4.90 \\
\hline & $1^{3} \mathrm{~A}_{1}\left(\pi \rightarrow \pi^{*}\right)$ & 1.63 & 1.62 \\
\hline & $1^{3} \mathrm{~B}_{2}\left(\pi \rightarrow \pi^{*}\right)$ & 1.14 & 1.09 \\
\hline \multirow[t]{12}{*}{ Imidazole } & Ground State & 3.91 & 3.79 \\
\hline & $2^{1} \mathrm{~A}^{\prime}\left(\pi \rightarrow \pi^{*}\right)$ & 4.71 & 3.60 \\
\hline & $3^{1} \mathrm{~A}^{\prime}\left(\pi \rightarrow \pi^{*}\right)$ & 3.72 & 2.31 \\
\hline & $4^{1} \mathrm{~A}^{\prime}\left(\pi \rightarrow \pi^{*}\right)$ & 4.14 & 5.18 \\
\hline & $1^{1} \mathrm{~A}^{\prime \prime}\left(n \rightarrow \pi^{*}\right)$ & 0.48 & 0.99 \\
\hline & $2^{1} \mathrm{~A}^{\prime \prime}\left(n \rightarrow \pi^{*}\right)$ & 3.34 & 3.09 \\
\hline & $1^{3} \mathrm{~A}^{\prime}\left(\pi \rightarrow \pi^{*}\right)$ & 3.00 & 2.99 \\
\hline & $2^{3} \mathrm{~A}^{\prime}\left(\pi \rightarrow \pi^{*}\right)$ & 4.56 & 4.51 \\
\hline & $3^{3} \mathrm{~A}^{\prime}\left(\pi \rightarrow \pi^{*}\right)$ & 4.83 & 4.15 \\
\hline & $4^{3} \mathrm{~A}^{\prime}\left(\pi \rightarrow \pi^{*}\right)$ & 4.88 & 4.32 \\
\hline & $1^{3} \mathrm{~A}^{\prime \prime}\left(n \rightarrow \pi^{*}\right)$ & 1.17 & 1.44 \\
\hline & $2^{3} \mathrm{~A}^{\prime \prime}\left(n \rightarrow \pi^{*}\right)$ & 3.86 & 3.67 \\
\hline
\end{tabular}

Continued on Next Page... 


\section{Molecular Physics}

Molecular Physics

Table B2 - Continued

\begin{tabular}{|c|c|c|c|}
\hline \multirow[t]{2}{*}{ Molecule } & \multirow[t]{2}{*}{ State } & \multicolumn{2}{|r|}{$\mathrm{CC} 2$} \\
\hline & & $\operatorname{TZVP}^{a}$ & aug-cc-pVTZ ${ }^{b}$ \\
\hline \multirow[t]{15}{*}{ Pyridine } & Ground State & 2.33 & 2.31 \\
\hline & $2^{1} \mathrm{~A}_{1}\left(\pi \rightarrow \pi^{*}\right)$ & 2.68 & 2.11 \\
\hline & $4^{1} \mathrm{~A}_{1}\left(\pi \rightarrow \pi^{*}\right)$ & 2.13 & 0.15 \\
\hline & $1^{1} \mathrm{~A}_{2}\left(n \rightarrow \pi^{*}\right)$ & 1.10 & 0.39 \\
\hline & $1^{1} \mathrm{~B}_{2}\left(\pi \rightarrow \pi^{*}\right)$ & 2.02 & 2.01 \\
\hline & $2^{1} \mathrm{~B}_{2}\left(\pi \rightarrow \pi^{*}\right)$ & 2.69 & 2.71 \\
\hline & $1^{1} \mathrm{~B}_{1}\left(n \rightarrow \pi^{*}\right)$ & 1.10 & 0.40 \\
\hline & $1^{3} \mathrm{~A}_{1}\left(\pi \rightarrow \pi^{*}\right)$ & 2.15 & 2.15 \\
\hline & $2^{3} \mathrm{~A}_{1}\left(\pi \rightarrow \pi^{*}\right)$ & 2.53 & 2.49 \\
\hline & $3^{3} \mathrm{~A}_{1}\left(\pi \rightarrow \pi^{*}\right)$ & 1.59 & 1.74 \\
\hline & $1^{3} \mathrm{~A}_{2}\left(n \rightarrow \pi^{*}\right)$ & 1.01 & 0.32 \\
\hline & $1^{3} \mathrm{~B}_{2}\left(\pi \rightarrow \pi^{*}\right)$ & 1.96 & 1.97 \\
\hline & $2^{3} \mathrm{~B}_{2}\left(\pi \rightarrow \pi^{*}\right)$ & 3.49 & 3.25 \\
\hline & $3^{3} \mathrm{~B}_{2}\left(\pi \rightarrow \pi^{*}\right)$ & 1.16 & 1.26 \\
\hline & $1^{3} \mathrm{~B}_{1}\left(n \rightarrow \pi^{*}\right)$ & 1.10 & 0.55 \\
\hline \multirow[t]{7}{*}{ Pyrimidine } & Ground State & 2.43 & 2.40 \\
\hline & $2^{1} \mathrm{~A}_{1}\left(\pi \rightarrow \pi^{*}\right)$ & 3.24 & 0.81 \\
\hline & $3^{1} \mathrm{~A}_{1}\left(\pi \rightarrow \pi^{*}\right)$ & 2.11 & 1.52 \\
\hline & $1^{1} \mathrm{~A}_{2}\left(n \rightarrow \pi^{*}\right)$ & 1.07 & 1.34 \\
\hline & $1^{1} \mathrm{~B}_{2}\left(\pi \rightarrow \pi^{*}\right)$ & 2.26 & 2.19 \\
\hline & $2^{1} \mathrm{~B}_{2}\left(\pi \rightarrow \pi^{*}\right)$ & 1.38 & 2.06 \\
\hline & $1^{1} \mathrm{~B}_{1}\left(n \rightarrow \pi^{*}\right)$ & 0.39 & 0.64 \\
\hline \multirow[t]{9}{*}{ Pyridazine } & Ground State & 4.36 & 4.33 \\
\hline & $2^{1} \mathrm{~A}_{1}\left(\pi \rightarrow \pi^{*}\right)$ & 3.64 & 3.61 \\
\hline & $3^{1} \mathrm{~A}_{1}\left(\pi \rightarrow \pi^{*}\right)$ & 4.07 & 2.15 \\
\hline & $1^{1} \mathrm{~A}_{2}\left(n \rightarrow \pi^{*}\right)$ & 1.21 & 1.84 \\
\hline & $2^{1} \mathrm{~A}_{2}\left(n \rightarrow \pi^{*}\right)$ & 1.50 & 2.08 \\
\hline & $1^{1} \mathrm{~B}_{2}\left(\pi \rightarrow \pi^{*}\right)$ & 5.30 & 3.98 \\
\hline & $2^{1} \mathrm{~B}_{2}\left(\pi \rightarrow \pi^{*}\right)$ & 3.98 & 4.01 \\
\hline & $1^{1} \mathrm{~B}_{1}\left(n \rightarrow \pi^{*}\right)$ & 1.10 & 1.72 \\
\hline & $2^{1} \mathrm{~B}_{1}\left(n \rightarrow \pi^{*}\right)$ & 1.66 & 2.25 \\
\hline \multirow[t]{5}{*}{ Formaldehyde } & Ground State & 2.32 & 2.38 \\
\hline & $1^{1} \mathrm{~A}_{2}\left(n \rightarrow \pi^{*}\right)$ & 1.25 & 1.38 \\
\hline & $1^{1} \mathrm{~B}_{1}\left(\sigma \rightarrow \pi^{*}\right)$ & 0.37 & 0.62 \\
\hline & $1^{3} \mathrm{~A}_{2}\left(n \rightarrow \pi^{*}\right)$ & 1.09 & 1.21 \\
\hline & $1^{3} \mathrm{~A}_{1}\left(\pi \rightarrow \pi^{*}\right)$ & 0.82 & 0.86 \\
\hline \multirow[t]{6}{*}{ Acetone } & Ground State & 2.86 & 2.97 \\
\hline & $2^{1} \mathrm{~A}_{1}\left(\pi \rightarrow \pi^{*}\right)$ & 2.94 & 2.42 \\
\hline & $1^{1} \mathrm{~A}_{2}\left(n \rightarrow \pi^{*}\right)$ & 1.45 & 1.84 \\
\hline & $1^{1} \mathrm{~B}_{1}\left(\sigma \rightarrow \pi^{*}\right)$ & 1.53 & 1.78 \\
\hline & $1^{3} \mathrm{~A}_{1}\left(\pi \rightarrow \pi^{*}\right)$ & 1.17 & 1.33 \\
\hline & $1^{3} \mathrm{~A}_{2}\left(n \rightarrow \pi^{*}\right)$ & 1.24 & 1.59 \\
\hline \multirow[t]{2}{*}{ Formamide } & Ground State & 3.86 & 3.84 \\
\hline & $2^{1} \mathrm{~A}^{\prime}\left(\pi \rightarrow \pi^{*}\right)$ & 2.00 & 2.69 \\
\hline
\end{tabular}

Continued on Next Page... 
Taylor EG Francis and I.T. Consultant

Table B2 - Continued

\begin{tabular}{|c|c|c|c|}
\hline \multirow[t]{2}{*}{ Molecule } & \multirow[t]{2}{*}{ State } & \multicolumn{2}{|r|}{$\mathrm{CC} 2$} \\
\hline & & $\mathrm{TZVP}^{a}$ & aug-cc-pVTZ ${ }^{b}$ \\
\hline \multirow{10}{*}{ Acetamide } & $3^{1} \mathrm{~A}^{\prime}\left(\pi \rightarrow \pi^{*}\right)$ & 1.80 & 2.93 \\
\hline & $1^{1} \mathrm{~A}^{\prime \prime}\left(n \rightarrow \pi^{*}\right)$ & 1.98 & 2.20 \\
\hline & $1^{3} \mathrm{~A}^{\prime}\left(\pi \rightarrow \pi^{*}\right)$ & 4.21 & 4.09 \\
\hline & $1^{3} \mathrm{~A}^{\prime \prime}\left(n \rightarrow \pi^{*}\right)$ & 1.80 & 1.99 \\
\hline & Ground State & 3.86 & 3.81 \\
\hline & $2^{1} \mathrm{~A}^{\prime}\left(\pi \rightarrow \pi^{*}\right)$ & 4.76 & 2.40 \\
\hline & $3^{1} \mathrm{~A}^{\prime}\left(\pi \rightarrow \pi^{*}\right)$ & 4.12 & 2.58 \\
\hline & $1^{1} \mathrm{~A}^{\prime \prime}\left(n \rightarrow \pi^{*}\right)$ & 1.69 & 1.77 \\
\hline & $1^{3} \mathrm{~A}^{\prime}\left(\pi \rightarrow \pi^{*}\right)$ & 3.82 & 3.54 \\
\hline & $1^{3} \mathrm{~A}^{\prime \prime}\left(n \rightarrow \pi^{*}\right)$ & 1.51 & 1.58 \\
\hline \multirow[t]{6}{*}{ Propanamide } & Ground State & 3.65 & 3.61 \\
\hline & $2^{1} \mathrm{~A}^{\prime}\left(\pi \rightarrow \pi^{*}\right)$ & 4.71 & 2.16 \\
\hline & $3^{1} \mathrm{~A}^{\prime}\left(\pi \rightarrow \pi^{*}\right)$ & 3.30 & 0.64 \\
\hline & $1^{1} \mathrm{~A}^{\prime \prime}\left(n \rightarrow \pi^{*}\right)$ & 1.56 & 1.59 \\
\hline & $1^{3} \mathrm{~A}^{\prime}\left(\pi \rightarrow \pi^{*}\right)$ & 3.82 & 3.46 \\
\hline & $1^{3} \mathrm{~A}^{\prime \prime}\left(n \rightarrow \pi^{*}\right)$ & 1.40 & 1.44 \\
\hline \multirow[t]{7}{*}{ Cytosine } & Ground State & 6.44 & 6.39 \\
\hline & $2^{1} \mathrm{~A}^{\prime}\left(\pi \rightarrow \pi^{*}\right)$ & 3.74 & 3.76 \\
\hline & $3^{1} \mathrm{~A}^{\prime}\left(\pi \rightarrow \pi^{*}\right)$ & 6.69 & 6.42 \\
\hline & $4^{1} \mathrm{~A}^{\prime}\left(\pi \rightarrow \pi^{*}\right)$ & 5.69 & 3.31 \\
\hline & $5^{1} \mathrm{~A}^{\prime}\left(\pi \rightarrow \pi^{*}\right)$ & 8.06 & 4.55 \\
\hline & $1^{1} \mathrm{~A}^{\prime \prime}\left(n \rightarrow \pi^{*}\right)$ & 1.76 & 0.74 \\
\hline & $2^{1} \mathrm{~A}^{\prime \prime}\left(n \rightarrow \pi^{*}\right)$ & 1.03 & 1.41 \\
\hline \multirow[t]{9}{*}{ Thymine } & Ground State & 4.24 & 4.26 \\
\hline & $2^{1} \mathrm{~A}^{\prime}\left(\pi \rightarrow \pi^{*}\right)$ & 5.50 & 5.20 \\
\hline & $3^{1} \mathrm{~A}^{\prime}\left(\pi \rightarrow \pi^{*}\right)$ & 2.68 & 1.96 \\
\hline & $4^{1} \mathrm{~A}^{\prime}\left(\pi \rightarrow \pi^{*}\right)$ & 6.88 & 6.00 \\
\hline & $5^{1} \mathrm{~A}^{\prime}\left(\pi \rightarrow \pi^{*}\right)$ & 1.40 & 1.00 \\
\hline & $1^{1} \mathrm{~A}^{\prime \prime}\left(n \rightarrow \pi^{*}\right)$ & 1.87 & 2.02 \\
\hline & $2^{1} \mathrm{~A}^{\prime \prime}\left(n \rightarrow \pi^{*}\right)$ & 4.26 & 4.12 \\
\hline & $3^{1} \mathrm{~A}^{\prime \prime}\left(n \rightarrow \pi^{*}\right)$ & 3.92 & 4.15 \\
\hline & $4^{1} \mathrm{~A}^{\prime \prime}\left(n \rightarrow \pi^{*}\right)$ & 2.63 & 2.33 \\
\hline \multirow[t]{9}{*}{ Uracil } & Ground State & 4.30 & 4.32 \\
\hline & $2^{1} \mathrm{~A}^{\prime}\left(\pi \rightarrow \pi^{*}\right)$ & 5.61 & 5.36 \\
\hline & $3^{1} \mathrm{~A}^{\prime}\left(\pi \rightarrow \pi^{*}\right)$ & 3.17 & 2.74 \\
\hline & $4^{1} \mathrm{~A}^{\prime}\left(\pi \rightarrow \pi^{*}\right)$ & 6.44 & 5.90 \\
\hline & $5^{1} \mathrm{~A}^{\prime}\left(\pi \rightarrow \pi^{*}\right)$ & 0.97 & 2.04 \\
\hline & $1^{1} \mathrm{~A}^{\prime \prime}\left(n \rightarrow \pi^{*}\right)$ & 3.33 & 1.60 \\
\hline & $2^{1} \mathrm{~A}^{\prime \prime}\left(n \rightarrow \pi^{*}\right)$ & 4.36 & 3.85 \\
\hline & $3^{1} \mathrm{~A}^{\prime \prime}\left(n \rightarrow \pi^{*}\right)$ & 3.97 & 3.52 \\
\hline & $4^{1} \mathrm{~A}^{\prime \prime}\left(n \rightarrow \pi^{*}\right)$ & 2.01 & 2.33 \\
\hline
\end{tabular}

${ }^{a}$ Results with the TZVP basis set from ref. [1]

${ }^{b}$ Results with the aug-cc-pVTZ basis set from this work. 

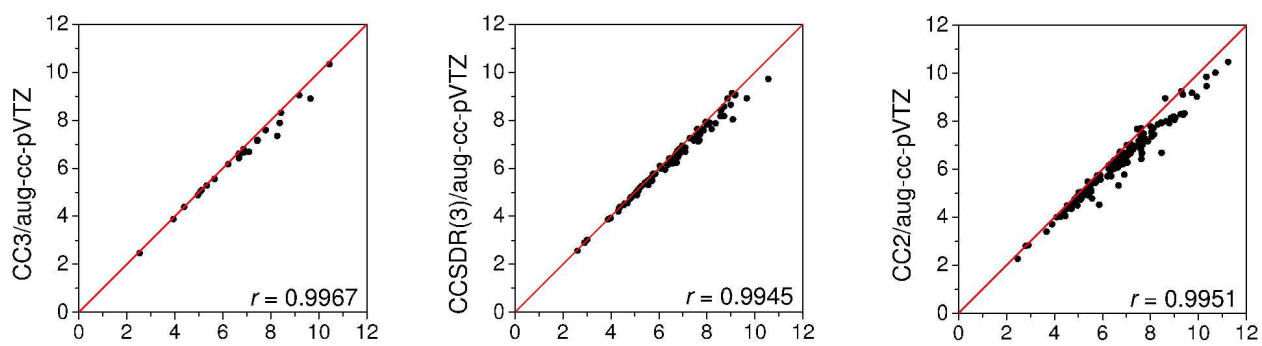

Correlation plots for the vertical excitation energies $(\mathrm{eV})$ of singlet excited states at the $\mathrm{CC} 3$, CCSDR(3), and CC2 levels: aug-cc-pVTZ vs. TZVP results. $255 \times 67 \mathrm{~mm}(600 \times 600 \mathrm{DPI})$ 
Histograms (in \%) of the deviations between aug-cc-pVTZ and TZVP vertical excitation energies (eV) of singlet excited states at the CC3, CCSDR(3), and CC2 levels $255 \times 67 \mathrm{~mm}(600 \times 600 \mathrm{DPI})$ 


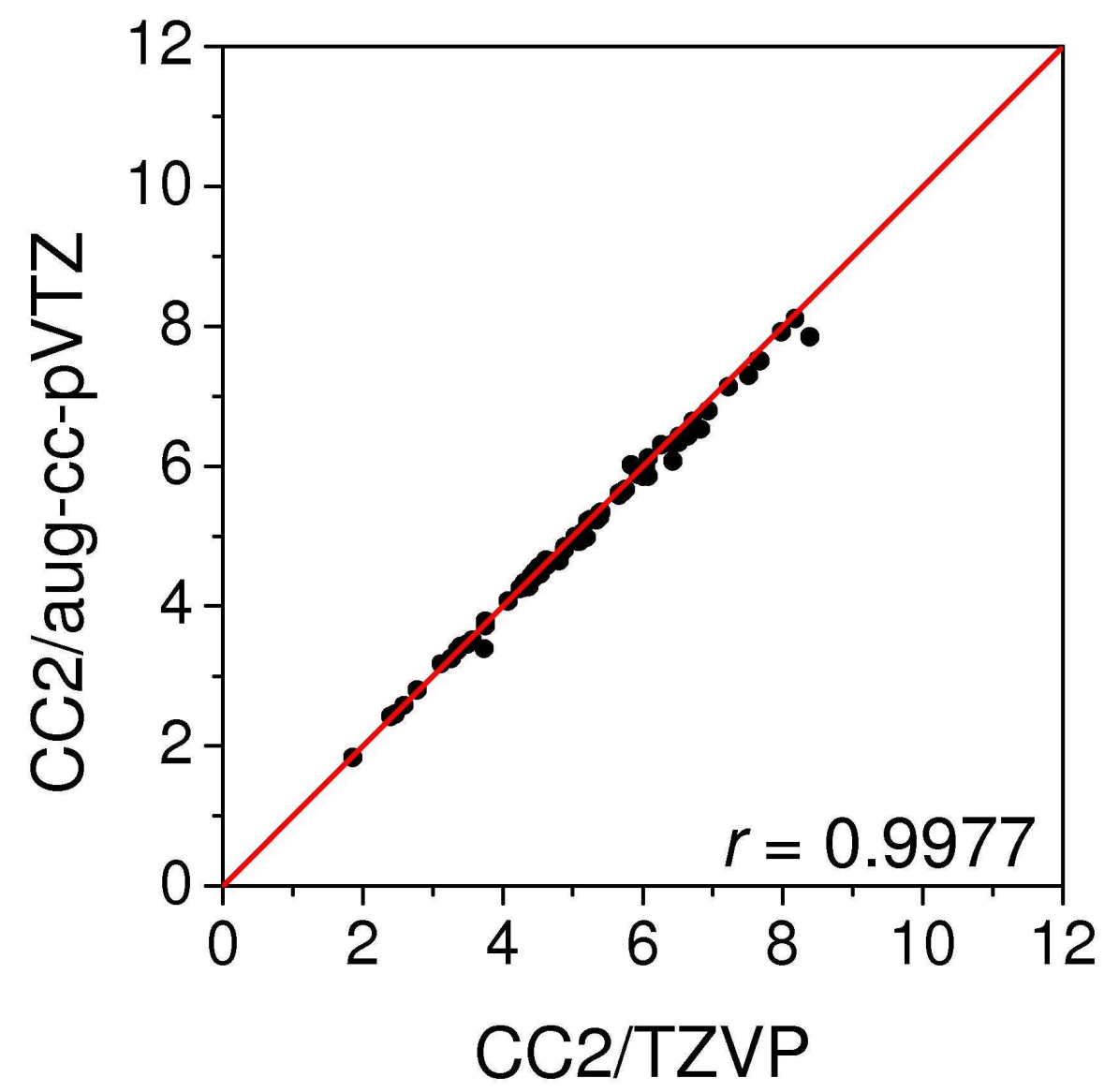

Correlation plot for the vertical excitation energies of triplet excited states: Basis set effects for CC2.

$81 \times 76 \mathrm{~mm}(600 \times 600 \mathrm{DPI})$ 

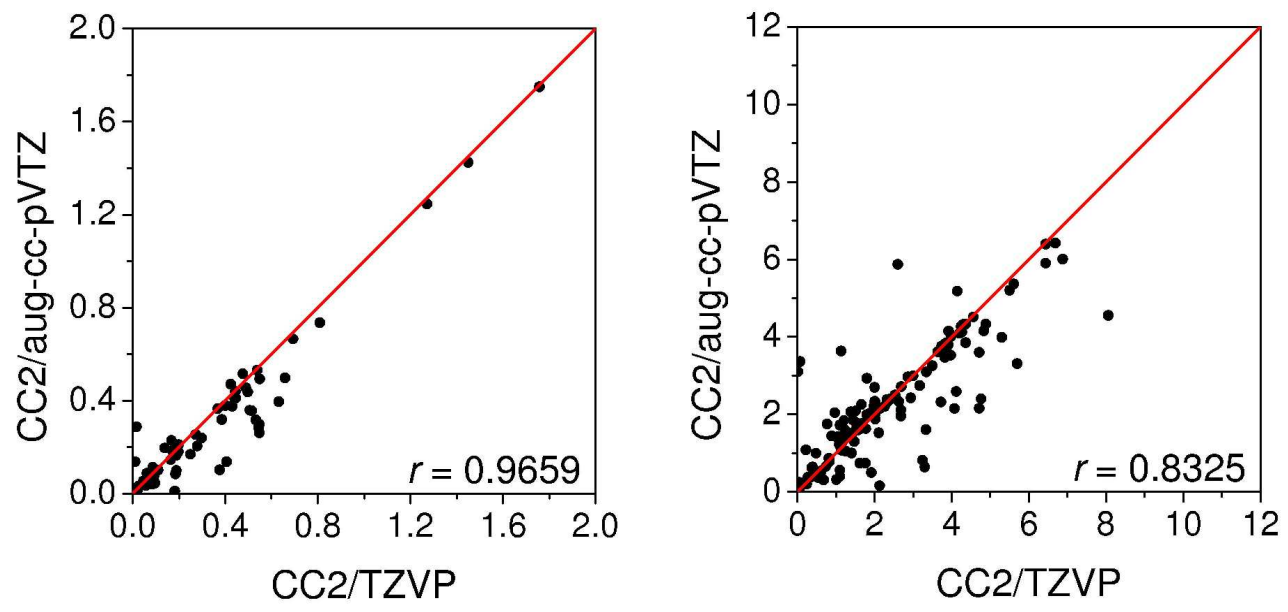

Correlation plots for (left) oscillator strengths and (right) dipole moments of singlet excited states: Basis set effects for CC2. $158 \times 77 \mathrm{~mm}(600 \times 600 \mathrm{DPI})$ 